FUENTEALBA, Pablo; LARRAÍN, Beatriz; BARRIGA, Omar. “ ¿Adhiere la ciudadanía a los principios del derecho penal y procesal penal? El caso del Gran Concepción, Chile”. Polít. crim. Vol. 13, No 25 (Julio 2018) Art. 7, pp. 233-263.

[http://www.politicacriminal.cl/Vol_13/n_25/Vol13N25A7.pdf]

\title{
¿Adhiere la ciudadanía a los principios del derecho penal y procesal penal? El caso del Gran Concepción, Chile
}

\section{Does the citizenry adhere to the principles of criminal law and criminal procedural law? The case of the area of greater Concepción, Chile}

\author{
Pablo J. Fuentealba-Carrasco \\ Sociólogo, MA en Investigación Social y Desarrollo (Universidad de Concepción, Chile) \\ Profesor Asistente, Departamento de Sociología, Universidad de Concepción, Chile. \\ pablofuentealba1@gmail.com \\ Beatriz E. Larraín-Martínez
}

Abogado, PhD in Derecho, Política y Sociedad (Northeastern University of Boston, USA)

Profesora Asociada, Facultad de Ciencias Jurídicas y Sociales, Universidad de Concepción, Chile.

blarrain@udec.cl

Omar A. Barriga

BA en Estudios Internacionales, MA y PhD en Sociología (Ohio State University, USA).

Profesor Asociado, Departamento de Sociología, Universidad de Concepción, Chile.

obarriga@udec.cl

\section{Resumen}

El artículo presenta los resultados de un estudio que mide el nivel de adhesión ciudadana a los principios del derecho penal liberal. La medición se realizó en el conurbano del Gran Concepción, Chile, con una muestra consecutiva de 369 casos, mediante un cuestionario compuesto de 46 ítems tipo Likert (Escala de adhesión a los principios del derecho penal: EAPDP), sometido a pruebas de confiabilidad y validez que permiten respaldar los hallazgos. Los resultados descriptivos se presentan diferenciadamente por escala general, subescalas e ítems, y revelan un bajo consenso en torno a los principios estudiados, lo que implica problemas de legitimidad del orden legal y la necesidad de desarrollar políticas orientadas a formar una cultura jurídica ciudadana.

Palabras clave: Actitudes Punitivas, Confianza en la justicia, Legitimidad, Populismo Penal, Punitivismo.

\begin{abstract}
The article presents the results of a study that measures the level of citizen's adherence to principles of the liberal criminal law and criminal procedural law. The measurement was carried out in the area of Greater Concepción, Chile, with a consecutive sample of 369 cases, through a questionnaire composed of 46 Likert-type items (Scale of adherence to the principles of criminal law: SAPCL), which was subjected to reliability and validity tests to support the findings. The descriptive results are presented differentially by general scale, subscale and items, and reveal a low level of adherence to the analyzed principles, which in
\end{abstract}


turn implies legitimacy problems of the legal order and the need to develop policies oriented to shape and ground a civic legal culture.

Keywords: Legitimacy, Penal Populism, Punitivism, Punitive Attitudes, Trust in Justice. Introducción

Durante los siglos XVIII y XIX, bajo la influencia del liberalismo de corte contractualista, cuyo núcleo es el iusnaturalismo, la ilustración puso como centro a la persona humana con sus derechos fundamentales, concibiéndola como una entidad sagrada que debía protegerse ante la posible violencia estatal ${ }^{1}$. En el ámbito penal y procesal-penal, esta defensa se expresó a través de un conjunto de derechos y garantías que se constituyeron en limitaciones ante el poder punitivo estatal, derivados -en su mayor parte- de los llamados principios del derecho penal $^{2}$. Nociones tales como la presunción de inocencia, la exigencia de plena prueba y la duda razonable, el principio de humanidad de las penas y de minimización de la violencia, la exigencia de legalidad penal como máxima taxatividad penal e interpretativa, la proporcionalidad de la pena, el derecho al debido proceso y a un juez independiente e imparcial, constituyen ejemplos de este conjunto de principios que fundamentaron doctrinalmente la esfera del ius puniendi, convirtiéndose en fundamentos para la mayoría de las democracias liberales occidentales ${ }^{3}$. Se conformó de este modo, el Estado de derecho ${ }^{4}$.

En Chile, se puede sostener que la mayor parte de los principios penales ha sido positivizada en la legislación nacional, puesto que éstos se reconocen en diversas instancias del ordenamiento jurídico. Se encuentran expresados en la Constitución Política de la República ${ }^{5}$, en los códigos Penal ${ }^{6}$ y Procesal Penal ${ }^{7}$ y, finalmente, por la vinculación del país a los tratados internacionales, tales como la Convención Americana sobre Derechos Humanos de $1969^{8}$ o el Pacto Internacional de Derechos Civiles y Políticos de $1966^{9}$.

\footnotetext{
${ }^{1}$ SILVA, Jesús-María, Aproximaciones al Derecho Penal Contemporáneo, España: Editorial José María Bosch, 1992, passim.

${ }^{2}$ RUIZ, Enrique, El Derecho Penal Sustantivo y el Proceso Penal. Garantías constitucionales básicas en la realización de justicia, España: Editorial Colex, 1997, passim; ZAFFARONI, Eugenio, Derecho Penal. Parte General, Argentina: Ediar Editores, 2001, passim; BUSTOS, Juan; HORMAZÁBAL, Hernán, Nuevo sistema de Derecho Penal, España: Ed. Trotta, 2004, passim.

${ }^{3}$ ETCHEBERRY, Alfredo, Derecho Penal: Parte general, Santiago: Ed. Jurídica de Chile, 1998; RUIZ, El Derecho, cit. nota 2; SILVA, Aproximaciones, cit. nota 1.

${ }^{4}$ BACIGALUPO, Enrique, Derecho Penal y el Estado de derecho, Santiago: Ed. Jurídica de Chile, 2005, passim.

${ }^{5}$ Por ej. en sus art. 19.e, 60.1, 62, 73, los cuales abordan la presunción de inocencia, legalidad, independencia de los tribunales, el principio de reserva legal, entre otros aspectos.

${ }^{6}$ Por ej. los artículos 1, 2, 10, 11, 12, 14 y 18, abordan, por ejemplo, aspectos tales como la responsabilidad penal (distinción dolo/culpa), graduación de la pena mediante sistema de atenuantes y agravantes, legalidad penal (taxatividad) e irretroactividad, entre otras nociones.

${ }^{7}$ Por ej. Art. 1, 2, 4 y 8, que tratan sobre la presunción de inocencia, la exigencia de un juez natural (parte del debido proceso) o el derecho a defensa entre otros principios.

${ }^{8}$ Los artículos 5, 7, 8 y 9, por ejemplo, explicitan la exigencia de humanidad de las penas, elementos del derecho al debido proceso y defensa, legalidad e irretroactividad, entre otros aspectos.

${ }^{9}$ Por ej. los artículos 7, 9, 10, 14.1, 14.3, 24 y 25 hacen referencia a los principios de humanidad de las penas, presunción de inocencia, derecho al debido proceso, igualdad ante la Ley y demás garantías, entre otros.
} 
FUENTEALBA, Pablo; LARRAÍN, Beatriz; BARRIGA, Omar. “ ¿Adhiere la ciudadanía a los principios del derecho penal y procesal penal? El caso del Gran Concepción, Chile”.

Por otro lado, desde la sociología política, en las democracias liberales, donde la voluntad ciudadana está representada teóricamente por el gobierno y el parlamento ${ }^{10}$, debiese presentarse cierta legitimidad social ante el orden legal establecido para que, sociológicamente, podamos definirlo como legítimo ${ }^{11}$.

Ahora bien, en el contexto actual del país es posible identificar una serie de eventos que pondrían en tela de juicio la aceptación ciudadana de los principios penales y procesalpenales. Opiniones ciudadanas expresadas en medios de comunicación y las redes sociales que cuestionan el derecho al debido proceso, la imparcialidad de los jueces, la presunción de inocencia o que incluso contravienen principios como el de humanidad de las penas, parecen ser frecuentes en la opinión pública. Además, algunos proyectos de ley presentados por el Ejecutivo que limitan la autonomía de los tribunales y el derecho al debido proceso ${ }^{12}$, ajusticiamientos ciudadanos que contravienen el principio de justicia estatal, entre otros eventos, no solamente pondrían en entredicho el apoyo ciudadano hacia estos principios, sino que podrían constituir indicadores de problemas de la legitimidad social del sistema, de confianza en la justicia o del paso hacia una nueva cultura penal.

Sin embargo, frente a estos indicios, podemos observar que se desconoce objetivamente cuál es el grado de aceptación o rechazo en torno a los principios del derecho penal de la legislación chilena por parte de la ciudadanía que carece de formación jurídica. ¿Adhiere la población en general a los principios del derecho penal y procesal penal chileno?

El interés por responder a estas preguntas orientó el desarrollo de esta investigación. De esta forma, el objetivo consistió en conocer el nivel de adhesión hacia los principios del derecho penal y procesal penal por parte de la ciudadanía de la zona conurbana de Concepción, Chile, que es la segunda zona más poblada del país. Todo esto para determinar los niveles de disenso o consenso en torno a los fundamentos del ordenamiento jurídico. La hipótesis de trabajo, aunque descriptiva, postula que -en términos generales- existirían insuficientes niveles de adhesión hacia estos principios, lo cual reflejaría problemas importantes de legitimidad.

En el contexto de este estudio, la disciplina jurídica fue utilizada para identificar y conceptualizar los principales principios penales (y procesal-penales) ${ }^{13}$. A partir de éstos se construyeron los ítems destinados a medir la adhesión a cada principio. La revisión bibliográfica no permitió elaborar una clasificación rígida y definitiva de éstos, ya que la literatura difería en el modo de exponerlos y categorizarlos. Por ello, cada uno de estos principios fue concebido de forma independiente para generar categorías a posteriori -a

\footnotetext{
${ }^{10}$ BOBBIO, Norberto, Liberalismo y Democracia, México: Ed. FCE, 1997, passim.

${ }^{11}$ FERRARI, Vicenzo, Derecho y Sociedad. Elementos para una Sociología del Derecho, Colombia: Editorial Universidad Externado de Colombia, Edición Kindle, 2012, passim.

${ }^{12}$ Por ej., el proyecto del Observatorio Judicial promovido en 2013. Éste habría afectado el Debido Proceso, especialmente la independencia e imparcialidad de los jueces, puesto que consistiría en una instancia creada y dirigida por el Poder Ejecutivo para sancionar y/o promocionar a los jueces de acuerdo a su desempeño. De esta forma los jueces considerados indulgentes (de acuerdo al número de condenas, sanciones aplicadas, etc.) tendrían evaluaciones deficientes (y viceversa). Esto afectaría o beneficiaría afectando su carrera judicial. Finalmente, el proyecto no fue presentado por los posibles vicios de inconstitucionalidad que implicaba.

${ }^{13}$ La investigación estudia la adhesión a los principios penales y procesal penales, que de ahora en adelante serán llamados sólo "principios penales" para refereirnos a ambos aspectos (considerando que el derecho penal puede ser sustantivo o adjetivo).
} 
Polit. crim. Vol. 13, № 25 (Julio 2018) Art. 7, pp. 233-263.

[http://www.politicacriminal.cl/Vol_13/n_25/Vol13N25A7.pdf]

través del Análisis Factorial Exploratorio- que resultasen coherentes con la teoría penal y así proceder a una posterior clasificación.

Teóricamente la investigación se aborda desde la sociología jurídica y la criminología por una parte y, desde la psicología evolutiva, por otra. Sin embargo, debe consignarse que, en esta publicación, la teoría cumple una función esencialmente orientadora, ya que no se establecen términos de correspondencia directos entre la teoría y la medición de las variables para apoyar o rechazar hipótesis. La teoría fue usada para la discusión de los resultados descriptivos, asumiendo que son interpretaciones posibles y coherentes teóricamente, pero no definitivas.

Sociológicamente, el fenómeno ha sido abordado, en primer término, desde las teorías de la legitimidad, entendiéndose por esta última la obediencia sustentada en el consenso, aceptación y creencia justificada en la validez del orden institucional y legal por considerarse preferible antes que otro posible como justificación subjetiva del origen del poder ${ }^{14}$. Cualquier foco de dominación política, incluidas administraciones, estructuras o regímenes pueden evaluarse en términos de legitimidad ${ }^{15}$. De esta forma, si bien puede existir cierto disenso ante preceptos particulares o ante ámbitos específicos, debiese presentarse un consenso general en torno al orden institucional en general y jurídico en particular para que éste pueda considerarse legítimo ${ }^{16}$. De este modo, la creencia y consenso subjetivos en un conjunto de principios trascendentales, de orden ético valóricos que inspiran la ley por parte de la ciudadanía, es lo que generaría la adhesión al orden legal tornándolo legítimo. En su nivel más profundo, esto se expresaría en la adhesión ciudadana hacia los principios penales que sustentan el ordenamiento penal y en una cierta correspondencia entre la opinión ciudadana y los principios del ius puniendi. En términos de Linz y Weber ${ }^{17}$, esta legitimidad permite que la obediencia a la ley se funde en la creencia más que en la coacción.

La legitimidad del orden institucional (el cual es una estructura históricamente construida pero externa y objetiva), se logra por medio del proceso de socialización. A través de éste, entendido como aprendizaje formal e informal, el mundo institucionalizado, que es externo y objetivo, se interioriza y replica en las conciencias subjetivas, constituyéndose en una realidad aprehensible, con sentido y válida para el sujeto. Por ello, la socialización constituye el proceso legitimador por excelencia ${ }^{18}$.

En el plano sociojurídico, la socialización permitiría generar una cultura jurídica entendida como:

"el conjunto de conocimientos, ideas y valores a través de los cuales los actores sociales seleccionan, interpretan, conceptualizan y organizan las informaciones concernientes al

\footnotetext{
${ }^{14}$ BERGER, Peter; LUCKMANN, Thomas, La construcción social de la realidad, España: Ed. Amorrortu, 2003, passim; LINZ, Juan, La Quiebra de las Democracias, Madrid: Ediciones Alianza, 1987, passim.

${ }^{15}$ MAZZUCA, Sebastián, "Legitimidad, Autonomía y Capacidad: Conceptualizando (una vez más) los poderes del Estado", Revista de Ciencia Política - Pontificia Universidad Católica de Chile, Vol. 32, N³ (2012), pp. 545-560, en: http://www.scielo.cl/scielo.php?pid=S0718090X20120003000 02\&script=sci_arttext [fecha de consulta: 8.10 .2015$]$.

${ }^{16}$ FERRARI, Derecho y Sociedad, cit. nota 11; LINZ, La Quiebra, cit. nota 14.

${ }^{17}$ LINZ, La Quiebra, cit. nota 14; WEBER, Max, Economía y Sociedad, México: Ediciones FCE, 2002, passim.

${ }^{18}$ BERGER/LUCKMANN, La construcción, cit. nota 14; LINZ, La Quiebra, cit. nota 14.
} 
FUENTEALBA, Pablo; LARRAÍN, Beatriz; BARRIGA, Omar. “ ¿Adhiere la ciudadanía a los principios del derecho penal y procesal penal? El caso del Gran Concepción, Chile”.

derecho y las traducen en estímulos, impresiones, convicciones y, eventualmente, en acciones jurídicas, es decir, pretensiones respaldadas por una fuerte y peculiar justificación normativa, es decir, por una fuerte legitimación" ${ }^{19}$.

La cultura jurídica permite que, a nivel de la opinión ciudadana, exista comunicación con el sistema jurídico, al ser éste comprendido por la población, produciéndose la conexión entre el sistema cultural y el derecho.

Las ideas anteriores pueden conectarse con la literatura internacional existente sobre punitividad pública. De esta forma, a partir del análisis de los sistemas penales de USA y UK, David Garland ha mostrado que, si bien el orden institucional de la modernidad penal ha logrado permanecer, en las últimas décadas se habría producido una declinación de los ideales modernos de rehabilitación, debido proceso y proporcionalidad de la pena. En cambio, reemergería la demanda por sanciones punitivas (sin gradualidad), la justicia expresiva (basada en la expresión del sentimiento público, por sobre el juicio experto), políticas criminales y leyes penales fundadas en el sentimiento popular más que en la ingeniería social, un sistema centrado casi únicamente en la víctima, surgimiento del populismo penal, entre otras transformaciones ${ }^{20}$. En esta misma línea, en otros contextos, diferentes autores comparten esta idea, resaltando como características la demanda por mayores sanciones, la difundida creencia de que las sentencias son indulgentes y de que, un aumento en la severidad del castigo, se traducirá en una disminución del delito ${ }^{21}$. Todo esto conduciría a modelo centrado en la seguridad ciudadana por sobre la idea de una estructura penal autolimitada (derecho penal mínimo) propia del modelo garantista liberal ${ }^{22}$.

Sin embargo, el estudio de la opinión pública hacia el sistema de justicia constituye un tópico complejo de abordar empíricamente. Las investigaciones sobre punitivismo varían en sus resultados dependiendo de la metodología empleada. De esta forma, en el caso de las actitudes punitivas, éstas son más altas cuando las preguntas son formuladas abstractamente (¿Cree usted que deberían aumentarse las penas?), ya que el sujeto recuerda los casos judiciales atípicos, no piensa en otras opciones de castigo, recuerda la información presentada en medios de comunicación, etc. En cambio, los niveles tienden a disminuir en contextos informados cuando, por ejemplo, bajo la metodología de caso-escenario al entrevistado se le proporciona información sobre el funcionamiento del sistema penal, sobre la historia del delincuente y/o sobre nuevas posibilidades de sanción alternativas. Asimismo, se evidencia una reducción del punitivismo cuando, bajo contextos informados, el mismo entrevistado

\footnotetext{
${ }^{19}$ FERRARI, Derecho y Sociedad, cit. nota 11, pos 3149.

${ }^{20}$ GARLAND, David. La cultura del control, España: Ediciones Gedisa, 2005, passim.

21 ROBERTS, Julian et al., Penal populism and public opinion: five lessons from five countries, United Kingdom: Ediciones Oxford University Press, 2003, passim; ROBERTS, Julian; HOUGH, Michael, Understanding public attitudes to criminal justice, United Kingdom: Ediciones Open University Press, 2005, passim.
}

${ }^{22}$ DIEZ RIPOLLÉS, José Luis, "El nuevo modelo Penal de la seguridad ciudadana”, Revista Electrónica de Ciencia Penal y Criminología, Vol. 6 Art.3 (2004), en: http://criminet.ugr.es/recpc/06/recpc06-03.pdf [Fecha de consulta: 03.08.2017]; DIEZ RIPOLLÉS, José Luis, "De la sociedad del riesgo a la seguridad ciudadana: un debate desenfocado", Revista Electrónica de Ciencia Penal y Criminología, Vol. 7, Art. 3 (2005), en http://criminet.ugr.es/recpc/07/recpc07-01.pdf [Fecha de consulta: 03.08.2017]. 
debe tomar las decisiones de sancionar ${ }^{23}$. Si bien esto se puede interpretar bajo el supuesto de que los niveles de punitivismo serían más bajos en la población de lo que se cree, a nuestro juicio consideramos que esta interpretación debería, más bien, comprenderse bajo la idea de que los niveles de punitivismo tienden a disminuir cuando los sujetos asumen roles (p.e. de juez), se informan o adquieren conocimientos nuevos que antes no tenían. Esto ayudaría a reforzar la idea de que posiblemente la educación o información tenga un papel importante en este aspecto como hemos señalado, lo cual sería compartido por varios autore ${ }^{24}$. $\mathrm{O}$ bien, desde nuestra perspectiva, podría decirse que el punitivismo 'manifiesto' (al que frecuentemente escucha la política criminal punitivista), sería más elevado que el 'latente' que emerge cuando el sujeto es cambiado de posición y/o informado a través estas técnicas. Por ello, sería importante mantener estos matices diferenciadores.

La literatura sobre punitivismo proporciona un sustento teórico importante para enmarcar esta investigación. Sin embargo, debe precisarse que la adhesión a los principios penales no debería equipararse con el punitivismo y/o actitudes punitivas. En este sentido, si bien hay bastante concordancia en varios aspectos entre estos dos temas, pudiendo concebirse como equiparables (p.e. entre gradualidad de la pena y punitivismo), en otros existen bastantes diferencias que harían cuestionable que los indicadores de la adhesión puedan ser considerados como una medida de punitivismo (p.e. debido proceso, legalidad). Así, a nuestro juicio deberíamos asumir que la medida de adhesión a los principios penales está vinculada al punitivismo, pero que no es plenamente equivalente. Esto sería compatible con la forma bajo la cual otros autores han abordado temas similares. Empleando técnicas muy distintas, han logrado constatar una importante correlación entre ambas variables, pero siempre tratándolas como aspectos distintos, distinguiendo claramente entre punitivismo y disposición ciudadana a abandonar protecciones procesales ${ }^{25}$.

Desde la psicología evolutiva-cognitiva del desarrollo moral iniciada por L. Kohlberg ${ }^{26}$, pensamos que el consenso en torno a estos principios exigiría cierto nivel de desarrollo ético, ya que los principios penales modernos responden a deducciones racionales que requieren ciertos niveles de abstracción y de elaboración racional para poder ser interiorizados. De este modo, una plena comprensión de estas nociones penales requeriría de niveles y estadios de desarrollo ético-cognitivos relativamente avanzados del sujeto. Específicamente,

\footnotetext{
${ }^{23}$ ROBERTS, Julian et al., "Public Opinion Towards the Lay Magistracy and the Sentencing Council Guideline: the effects of information on attitudes", British Journal of Criminology, Vol. 52, $\mathrm{N}^{\circ} 6$ (2012) pp. 1072-1091 en: https://academic.oup.com/bjc/article-lookup/doi/10.1093/bjc/azs024 [Fecha de consulta 29.07.2017]; VARONA, Daniel, "Ciudadanos y actitudes punitivas: un estudio piloto de población universitaria española", Revista Española de Investigación Criminológica, Vol. $6 \mathrm{~N}^{\circ} 1 \quad$ (2008) pp. 1-38 en: http://www.criminologia.net/pdf/reic/ano6-2008/a62008art1.pdf [Fecha de consulta: 24.07.2017]; VARONA, Daniel, "Somos los españoles punitivos?: actitudes punitivas y reforma penal en España", Revista InDret, Vol. 9, $\mathrm{N}^{\circ} 1$ (2009), pp. 1-31 en: http://www.indret.com/pdf/599.pdf [Fecha de consulta:25.07.2017]; ROBERTS, Understanding, cit. nota 21.

${ }^{24}$ ROBERTS et al., Penal populism, cit. nota 21; TYLER, Tom; BOECKMANN, Robert, "Three strikes and you are out, but why? The psychology of public support for punishing rule-breakers", en Law and Society Review, Vol. $\quad 31, \quad \mathrm{~N}^{\circ} \quad 2 \quad$ (1997), $\quad$ pp. $237-266$ en http://www.jstor.org/stable/3053926?seq=1\#page scan tab contents [Fecha de Consulta: 04.08.2017]

${ }^{25}$ TYLER/BOECKMANN, "Three strikes", cit. nota 25.

${ }^{26}$ HERSH, Richard; PAOLITO, Diana; REIMER, Joseph, El crecimiento moral, de Piaget a Kohlberg, Madrid: Ediciones Narcea, 1988, passim.
} 
FUENTEALBA, Pablo; LARRAÍN, Beatriz; BARRIGA, Omar. “ ¿Adhiere la ciudadanía a los principios del derecho penal y procesal penal? El caso del Gran Concepción, Chile”.

consideramos que el adecuado entendimiento y adhesión a los principios supone el desarrollo y el ejercicio de una capacidad fundamental que es la de "asumir roles", entendida como la habilidad del sujeto para situarse mentalmente en el lugar de otros, lo que permite elaborar juicios éticos y evaluar imparcialmente un principio de acción ${ }^{27}$. A través de esta capacidad, el sujeto no juzga un evento sólo desde su punto de vista particular, sino desde la perspectiva de los diferentes sujetos involucrados (víctima, acusado, condenado, jueces, etc.) hasta llegar a una evaluación general, objetiva y, de este modo, puede elaborar un juicio imparcial. El sujeto es capaz de ubicarse en el lugar de otro, pudiendo comprender que una regla es racional y coherente en la medida en que acepta su aplicación para otros. Pero también aceptaría y consideraría justa su aplicación aunque él mismo se viese perjudicado por ella, reflejándose la consistencia ética. Por ello, pensamos que el individuo que no adhiere a los principios penales, posiblemente no ha desarrollado (o ejercitado) plenamente la "capacidad de asumir roles" en el ámbito penal, ya que no se sitúa mentalmente en el lugar de un acusado, de un condenado o de un juzgador. Por este motivo, no elaboraría, por ejemplo, la hipótesis de "qué ocurriría si él o algún familiar fuese acusado o condenado por un delito". Al no realizar este ejercicio, el sujeto tendería a negar derechos y garantías a "otros" extraños, pero en cambio exigiría y consideraría justo, por ejemplo, que se presumiera su propia inocencia, que se dispusiera de tribunales imparciales y de un debido proceso para su propia defensa. Al no realizar el ejercicio de asunción de roles, el individuo no logra comprender la racionalidad, validez y universalidad del principio, elaborando juicios inconsistentes como los ejemplificados. Por ello, al presentarse en la sociedad bajos niveles cognitivo-evolutivos de desarrollo moral, como muestran diversos estudios en psicología ${ }^{28}$, dificultaría la posibilidad de comprender cognitivamente la racionalidad de estos principios y así apoyarlos.

De esta manera, aquí se conjugan tres elementos importantes. Primero, la tendencia en muchos países hacia el aumento de la punitividad pública. Segundo, desde la socialización, el hecho de que en Chile no ha habido políticas educacionales orientadas a formar una ciudadanía con una cultura jurídica básica que conozca y comprenda las ideas sobre las que descansa el derecho penal moderno. Finalmente, la presencia de insuficientes niveles cognitivo-evolutivos de desarrollo moral que dificultarían la comprensión de los principios. Por este motivo, a modo de hipótesis (aunque sólo exploratoria), anticiparíamos bajos niveles de adhesión en la población hacia estos principios fundamentales.

Finalmente, desde una óptica explicativa o correlacional, la adhesión a los principios penales podría encontrarse asociada con la victimización, exposición (o confianza) en los medios de comunicación y/o con factores sociodemográficos. Esto debido a que variables de este tipo

\footnotetext{
${ }^{27}$ HERSH/PAOLITO/REIMER, El crecimiento, cit. nota 26.

${ }^{28}$ Por lo general, gran parte de las investigaciones en psicología moral cognitivo-evolutiva muestran que la mayor parte de la población en los diferentes países no superaría los niveles intermedios o convencionales (aceptando la norma de grupo o social concreta), o bien se ubicaría en niveles inferiores (orientados únicamente hacia la retribución y el beneficio). Estos estudios se han desarrollado empleando escalas abreviadas del test de Kohlberg. Consultar en: ROBLES, Víctor, "La complementación de la discusión de dilemas con la lectura teórica para una eficaz intervención en el juicio moral”, International Journal of Psychological Research, Vol. 6, $\mathrm{N}^{\circ} 1$ (2013), pp. 84-93, en: http://www.scielo.org.co/pdf/ijpr/v6n1/v6n1a10.pdf [Fecha de consulta: 10.01.2015]; MATHIESEN, María Elena, et al., "Familia, Permisividad y Juicio Moral en Estudiantes de Enseñanza Media de la Provincia de Concepción”, Revista Psykhé Vol. 13, No1 (2004), pp. 3-20, en: http://www.scielo.cl/scielo.php?script=sci_arttext\&pid=S071822282004000 100001\&lng=es\&nrm=iso [fecha de consulta: 20.10.2015].
} 
se han considerado como predictores o correlatos de variables criminológicas tales como el miedo al delito ${ }^{29}$, la confianza en la justicia ${ }^{30}$ o el mismo punitivismo ${ }^{31}$. Sin embargo, estos ámbitos no se abordaron empíricamente en este trabajo, centrándolos sólo en describir los niveles de consenso-disenso en torno a los principios penales.

Tenemos presente que abordar una investigación de forma descriptiva no permite resolver interrogantes que el lector podría considerar importantes, como aquellas relativas a las causas o correlatos de la adhesión. Sin embargo, esto hubiese requerido análisis multivariados o bivariados que exceden la finalidad de este artículo. Por ello, y teniendo presente que no existen mediciones previas en torno a este tema, en esta etapa hemos privilegiado responder a la pregunta sobre el nivel de consenso ciudadano en torno a los principios con mayor detalle descriptivo e intentar resolver interrogantes causales en futuras publicaciones.

El fenómeno estudiado tiene especial importancia desde el punto de vista tanto disciplinar como práctico. Desde el punto de vista disciplinar, presenta aportes teóricos, metodológicos y empíricos. Teóricamente, permite conocer el vínculo entre el sistema jurídico y el sistema cultural, porque describe la cultura jurídica de una sociedad y sus opiniones sociales en torno a los fundamentos de la legislación penal, lo cual constituye uno de los temas esenciales de la sociología jurídica ${ }^{32}$. Esto permite conocer el nivel de consenso o disenso en torno al ordenamiento jurídico y la consecuente legitimidad de este ámbito del ordenamiento jurídico. Metodológicamente, la investigación aporta con la construcción de un instrumento que posee propiedades de confiabilidad y validez apropiadas para medir la adhesión a los principios del derecho penal. El cuestionario elaborado, como todo otro, puede perfeccionarse, pero, además, puede convertirse en un modelo para otros instrumentos que midan los niveles de aceptación social de otros principios penales, o bien para conocer la adhesión hacia los principios jurídicos de otras ramas del derecho tales como el derecho laboral, tributario, comercial, entre otras. Empíricamente, el estudio proporciona información que permite estimar la tendencia de la población ante los principios penales y conocer cuál es el nivel de consenso o disenso, de aceptación o rechazo en torno a éstos. A partir de estos datos, es posible hipotetizar (en esta etapa) sobre la legitimidad y las causas asociadas a los niveles de adhesión y consenso. El tema propuesto se torna importante en países con sistemas jurídicos basados en estos principios y/o en sociedades que están implementando reformas penales y/o

\footnotetext{
${ }^{29}$ Véase por ejemplo, DAMMERT, Lucía; MALONE, Mary Fran, "Fear of Crime or Fear of Life? Public Insecurities in Chile", Bulletin of Latin American Research 22(1) (2003), pp. 79-101, en: http://dx.doi.org/10.1111/1470-9856.00065 [visitado el 22.05.15]; FUENTEALBA, Pablo; ROJAS, Juan; BARRIGA, Omar, "Diferencias en la precepción de inseguridad a nivel cognitivo y emocional de acuerdo al perfil sociodemográfico y político. Estudio del Gran Concepción, Chile", en Revista Política Criminal, Vol. 11, $\mathrm{n}^{\circ} 2$ (2016) pp. 620-655, en http://www.politicacriminal.cl/Vol_11/n_22/Vol11N22A8.pdf [Fecha de consulta: 25.07.2017]; GIBSON, Chris et al., "Social Integration, Individual Perceptions of Collective Efficacy, and Fear of Crime In Three Cities", Justice Quarterly, Vol. 19, $\mathrm{N}^{\circ} 3$ (2002), pp. 537-564, en: http://dx.doi.org/10.1080/07418820200095341 [visitado el 26.07.2017].

${ }^{30}$ CALDEIRA, Gregory; GIBSON, James, "The etiology of the public support of for the supreme court, en American Journal of Political Science", Vol. 36, $\mathrm{N}^{\circ} 3$ (1992) pp. 635-664 en http://www.jstor.org/stable/2111585 [Fecha de Consulta: 05.08.2017]

${ }^{31}$ ROBERTS, et al., Understanding, cit. nota 21; TYLER/BOECKMANN, "Three strikes ..." cit. nota 25.

${ }^{32}$ FERRARI, Derecho y Sociedad, cit. nota 11; FUCITO, Felipe, Sociología del Derecho. Del Orden Jurídico y de sus Condicionantes Sociales, Argentina: Ed. Universidad, 1999.
} 
FUENTEALBA, Pablo; LARRAÍN, Beatriz; BARRIGA, Omar. “ ¿Adhiere la ciudadanía a los principios del derecho penal y procesal penal? El caso del Gran Concepción, Chile”.

procesal-penales inspiradas en estos principios, las cuales debiesen contar con suficientes niveles de legitimidad social para su adecuado funcionamiento.

Desde el punto de vista práctico, este tipo de investigación, y sus desarrollos posteriores, pueden constituir un insumo para políticas educacionales y/o informacionales orientadas a la socialización de los principios en la ciudadanía y, de esta forma, contribuir al mejoramiento de los niveles de legitimidad.

Entonces, podemos responder empíricamente con un instrumento que dispone de propiedades de confiabilidad y validez a esta pregunta fundamental: ¿Acepta la ciudadanía los principios esenciales del derecho penal moderno y en qué medida?

\section{Método}

\subsection{Diseño}

Se utilizó un enfoque cuantitativo, ya que los datos se analizaron estadísticamente. Se empleó el método de encuesta con cuestionario estandarizado como instrumento. El estudio fue transversal, no experimental y con datos primarios, producidos específicamente para poder cumplir con los objetivos de investigación propuestos.

\subsection{Muestra}

Se utilizó una muestra no probabilística consecutiva compuesta por 369 entrevistados pertenecientes al Conurbano del Gran Concepción, Región del Bío-Bío, Chile, que para el año 2014 presentaba una proyección de población de 1.040 .348 habitantes $^{33}$. La muestra presentó un 5,1\% de margen de error para un 95\% de nivel de confianza. Para entrevistar, se seleccionaron aleatoriamente sectores pertenecientes a las diferentes comunas del conurbano del Gran Concepción. Desde ahí se seleccionaron hogares y se entrevistó a una persona por hogar.

Como criterio de elegibilidad de los entrevistados, se consideró que a) fuesen mayores de 18 años, b) fuesen residentes del conurbano de Concepción y c) se procuró mantener cierto nivel de proporción muestral de ciertas categorías sociodemográficas básicas de sexo, edad, nivel educacional y comuna, con el objetivo de obtener un perfil heterogéneo de los entrevistados ${ }^{34}$.

Las edades de los entrevistados se encuentran entre los 18 y 81 años, con una media de 35,8 años y una desviación estándar de 15,3 años. Un 55\% corresponde a mujeres. Un 2,4\% no

\footnotetext{
${ }^{33}$ Esta cifra corresponde a la suma de los totales de población, correspondientes al año 2002, de cada una de las comunas del Gran Concepción (Concepción, Coronel, Chiguayante, Hualpén, Hualqui, Lota, Penco, San Pedro de la Paz, Talcahuano y Tomé), disponibles en: INSTITUTO NACIONAL DE ESTADÍSTICAS, “Actualización de Población 2002-2012 y Proyecciones 2015-2020 Provincia de Concepción”, Santiago de Chile: INE (2015), en: http://www.inebiobio.cl/archivos/files/pdf/poblacion/Proyecciones/PRESENTACION \%20PROYECCIONES\%20DE\%20POBLACION\%20PROV\%20CONCEPCION.pdf [visitado el 05.07.2016].

${ }^{34}$ Considerando que no se trataba de una muestra por cuotas proporcionales, no era un requisito que las proporciones se cumpliesen estrictamente. Más bien se esperaba cuidar las proporciones para evitar que el perfil fuese homogéneo y lograr variabilidad en la respuesta.
} 
tiene ningún tipo de estudios, o bien posee sólo estudios básicos completos/incompletos, un 23,6\% tiene Estudios Medios completos/incompletos, un 10\% cuenta con estudios técnicos completos/incompletos, un $13 \%$ con educación técnica profesional completa/incompleta, un $46,9 \%$ con estudios universitarios completos/incompletos y un 3,1\% con Estudios de Postgrado completos/incompletos. El 14,3\% se autodefine como derecha/centro-derecha, un $12,8 \%$ como centro, un $29 \%$ como izquierda/centro-izquierda y un 43,9\% como apolítico/sin ubicación.

Una de las principales limitaciones del estudio es que la muestra empleada no es probabilística, por lo cual no es posible generalizar los resultados estimando el error muestral. Sin embargo, la muestra es adecuada en tamaño y los grupos básicos que componen la población de interés se encuentran representados, lo cual permitiría con ciertas precauciones, conocer la tendencia poblacional respecto al tema estudiado.

\subsection{Procedimiento}

Los datos fueron recogidos en diciembre de 2014 por 20 encuestadores capacitados. El instrumento fue aplicado cara a cara por los entrevistadores, con una duración aproximada de 30-35 minutos.

\subsection{Instrumento}

Se utilizó un cuestionario con preguntas tipo Likert para medir adhesión a los principios penales desarrollado por Fuentealba y Barriga ${ }^{35}$, el cual cuenta con 46 reactivos para medir directamente el consenso en torno a 21 Principios Penales y Procesal-Penales (más 3 indirectos). La adhesión a estos principios no es medida en abstracto, sino vinculando cada principio penal a delitos de alta connotación social, los que son clasificados en dos niveles polares: alto rechazo social (homicidio, pedofilia y violación) y bajo rechazo social (hurtos, cuento del tío, carterazos, lanzazos, entre otros ${ }^{36}$ ). Los delitos expuestos se presentan como ejemplos de cada nivel para el entrevistado, más que como referencia a delitos específicos, con la finalidad de evaluar la adhesión en dos contextos polares diferentes. De esta forma, el entrevistado debe señalar su nivel de acuerdo o desacuerdo ante las afirmaciones planteadas (con cinco categorías desde "Muy en Desacuerdo" hasta "Muy de Acuerdo", utilizando una categoría central de "Ni de acuerdo ni en desacuerdo"), las cuales conjugan el principio penal con los delitos clasificados en estos dos niveles. Como consecuencia cada principio medido posee su par lógico de reactivos. Para todas las afirmaciones se usan los mismos ejemplos de

\footnotetext{
35 FUENTEALBA, Pablo; BARRIGA, Omar, "Primera aproximación a la construcción de una Escala de Adhesión a los principios del Derecho Penal (EAPDP)”. Estudio piloto en el conurbano del Gran Concepción, Chile", en Revista Internacional de Sociología, Vol. 75, No2 (2017), pp. ¿e060?, en http://dx.doi.org/10.3989/ris.2017.75.2.15.103 [Fecha de consulta: 28.07.2017]

${ }^{36}$ Cuento del tío: corresponde a un tipo de estafa menor, que usa el engaño y astucia para aprovecharse de la inocencia de las víctimas (p.e. cambiar dinero por un boleto de lotería supuestamente premiado). Carterazo o lanzazo: corresponde al robo por sorpresa. El delincuente se apropia de especies sin uso de violencia, aparentando riñas o maniobras que generen confusión en lugares concurridos, quitando pertenencias (celulares, billeteras u objetos de los bolsillos) dándose a la fuga rápidamente, o bien aprovechando los descuidos de las personas para hurtarles (que alguien una vez que ha llegado a su casa repare en que le quitaron su billetera en el bus). A diferencia del asalto, no emplea amenazas o intimidación, ni violencia.
} 
FUENTEALBA, Pablo; LARRAÍN, Beatriz; BARRIGA, Omar. “ ¿Adhiere la ciudadanía a los principios del derecho penal y procesal penal? El caso del Gran Concepción, Chile”.

delitos con el fin de no perder la equivalencia entre los ítems. Considerando que la población general estudiada carece de conocimientos jurídicos especializados, y por lo tanto, puede desconocer los principios penales, así como muchos de los conceptos y términos legales ("irretroactividad", "taxatividad", "hurto", "imputado", "ministerio público"), los reactivos han sido traducidos desde el lenguaje técnico al lenguaje coloquial y corriente. De esta forma, las preguntas son formuladas como expresiones accesibles a sujetos de diversos niveles educacionales, pero donde cada ítem contiene el concepto del principio que se busca medir. Como ejemplo, los reactivos han sido formulados de la siguiente forma (para principio de plena prueba y duda razonable):

3.-Cuando finaliza un juicio por homicidio, violación o pedofilia, los jueces deberían castigar a un acusado cuando hay más probabilidades de que sea culpable, aunque puedan existir ciertas dudas fundadas de que tal vez no cometió el delito.

31.-Cuando finaliza un juicio por robo sin violencia, mecheo, lanzazo o cuento del tío, los jueces deberían castigar a un acusado cuando hay más probabilidades de que sea culpable, aunque puedan existir ciertas dudas fundadas de que tal vez no cometió el delito.

Posteriormente, los ítems fueron distribuidos aleatoriamente en la escala. Los delitos de rechazo social intermedio (como robo con violencia y asaltos, delito de lesiones) se excluyeron de la medición con el fin de reducir la extensión del cuestionario y para evitar la posible ambigüedad entre el nivel intermedio y los polos extremos de delitos usados. Además, no se incluyeron delitos cuya respuesta pudiese encontrarse condicionada por variables políticas o valóricas (delitos de consumo y tráfico de drogas, terrorismo, estafas de grandes empresas), ya que estas variables no fueron controladas en la investigación, optándose por aquellos delitos que se supone que presentaban un rechazo transversal.

Los principios y/o conceptos medidos en la escala fueron: (1) principio de culpabilidad, (2) principio de responsabilidad penal especial -distinción de responsabilidad entre adultos y adolescentes-, (3) trayectoria criminal (irreprochable conducta anterior), (4) reparación del daño causado, (5) principio de plena prueba (y duda razonable), (6) derecho de defensa material, (7) derecho a defensa técnica, (8) derecho a juez imparcial e (9) independiente, (10) legalidad de la prueba, (11) personalidad de la pena (o intrascendencia de la pena), (12) presunción de inocencia, (13) principio de peligrosidad, (14) subsidiariedad sancionatoria, (15) humanidad de las penas, (16) control de la ejecución penal, (17) sistema estatal de justicia, (18) legalidad penal como máxima taxatividad penal e (19) interpretativa, (20) derechos sociales y dignidad de los acusados y (21) rigor probatorio. Otros principios no medidos directamente, pero implícitos en los reactivos, fueron reserva legal en lo penal, irretroactividad penal e In Dubio Pro Reo. Además, si bien para cada principio se contaba con ítems específicos destinados a medirlos, algunos fueron evaluados en más de un reactivo. También, algunos de estos ítems resultaban complejos porque medían principalmente un rasgo, pero indirectamente podían vincularse y medir otros principios penales.

\subsection{Confiabilidad y validez de la escala}

Cuando se miden conceptos internos o psicológico-actitudinales (p.e. personalidad, valores, inteligencia) que, por no ser variables observables directamente, resultan difíciles de estudiar (como en nuestro caso, la adhesión a los principios penales), es importante establecer las propiedades de confiabilidad y validez de las mediciones, ya que esto permite establecer que efectivamente está midiendo la variable que se busca medir y con un adecuado nivel de 
precisión (bajo nivel de error). Las propiedades psicométricas de la Escala de Adhesión a los Principios Penales (EAPDP), fueron publicadas por Fuentealba y Barriga ${ }^{37}$. Así, la validez de contenido fue establecida mediante juicio experto compuesto por 10 especialistas, de los cuales 6 provenían del ámbito del derecho (profesionales y académicos) y 4 del ámbito de la metodología (psicología y sociología). La validez de constructo se estableció mediante Análisis Factorial Exploratorio (AFE) ${ }^{38}$. Los 46 ítems fueron agrupados en 6 factores que explican el $45.1 \%$ de la varianza inicial, con cargas factoriales sobre 0,369 en la matriz de estructura. Esto muestra que el fenómeno de la adhesión a los principios penales es multidimensional, y que poseería 6 dimensiones. Una vez que los factores fueron conceptualizados, se procedió a la construcción de las subescalas y de la escala general.

La confiabilidad como consistencia interna se estableció mediante alpha de Cronbach. Cada una de las subescalas presentó apropiados coeficientes (0,676 la más baja y 0,865 la más alta). La adecuada fiabilidad dentro de cada subescala indica que sus ítems miden un mismo concepto o que hay un patrón de respuesta coherente dada su elevada correlación, pero que cada ítem aporta información propia y diferenciada, puesto que se descartaron correlaciones sobre 0,900 (no habiendo información redundante).

Además, los autores efectuaron un AFE de segundo orden entre los puntajes de las seis subescalas. Se estableció que las seis dimensiones poseen un único factor o misma variable latente común conceptualizable como Adhesión a los principios del derecho penal. Se aplicó un test alpha Cronbach entre estos mismos puntajes, obteniéndose una consistencia interna adecuada $(\alpha=0,753)$ entre los seis factores. Esto indica que las subescalas están altamente correlacionadas y son consistentes entre sí. Esto implica que, debido a la correlación existente entre ellas, quien apoya los principios en una subescala presentará, probablemente, una tendencia a apoyar los principios en las restantes subescalas y viceversa.

A partir de estos análisis se obtuvieron las siguientes subescalas y escala general:

\footnotetext{
${ }^{37}$ FUENTEALBA/BARRIGA, "Primera aproximación”, cit. nota n 35 .

${ }^{38}$ Recordamos que una vez que se ha realizado la recolección de datos, el Análisis Factorial Exploratorio (AFE) busca resumir la información identificando agrupaciones/conjuntos de ítems en función de la estructura de correlaciones que hay entre las respuestas de los encuestados. Las preguntas/ítems se vinculan y agrupan entre sí en la medida en que poseen una variable latente común (llamado "Factor") que las agrupa, explicando la alta correlación existente en las respuestas de los entrevistados a esas preguntas y explicando la diferencia respecto a los factores restantes que explican otro conjunto de preguntas (con los que no poseen una estructura/patrón de respuesta común desde el punto de vista estadístico). Esta variable latente puede ser considerada válida si cumple con ciertos criterios estadísticos (cargas superiores a 0,300) y en la medida en que es posible asignarle un término o concepto teórico coherente (por ej. "ansiedad en público", "ansiedad ante evaluaciones", "ansiedad en situaciones íntimas", etc. para una escala de ansiedad), lo cual vuelve interpretable al factor.

En este estudio se esperaba que los factores pudiesen ser identificados e interpretados con conceptos teóricamente coherentes tales como: adhesión al debido proceso, adhesión a la legalidad penal u otros propios de la disciplina. Debe tenerse presente que, dado que agrupa correlaciones desde las respuestas entre entrevistados, no necesariamente se corresponderían plenamente con la teoría jurídica, pero se esperaba una coherencia teórica general para considerar válida la escala. Además, las llamadas cargas factoriales deben ser elevadas (en general sobre 0,300) para poder mantener los ítems. Si cada factor posee adecuadas cargas factoriales y una apropiada consistencia interna (fiabilidad cercana o sobre 0,7 ), entonces es posible considerar que la escala es válida, confiable y, posteriormente, podemos construir subescalas dentro de una escala general o global.
} 
FUENTEALBA, Pablo; LARRAÍN, Beatriz; BARRIGA, Omar. “ ¿Adhiere la ciudadanía a los principios del derecho penal y procesal penal? El caso del Gran Concepción, Chile”.

a) Adhesión a la gradualidad de la pena $(\alpha=0,865)$,

b) Adhesión al derecho al debido proceso y personalidad de la pena $(\alpha=0,797)$,

c) Adhesión a la intervención mínima y legalidad en la aplicación de penas y medidas $(\alpha=0,720)$,

d) Adhesión al principio de humanidad de las penas desde un sistema estatal de justicia $(\alpha=0,781)$,

e) Adhesión al principio de legalidad penal $(\alpha=0,810)$,

f) Adhesión a los derechos sociales y de trato a condenados y acusados $(\alpha=0,676)$,

g) Escala General de Adhesión a los principios del derecho penal $(\alpha=0,753)$.

Los resultados descriptivos de la Escala de adhesión a los principios del derecho penal (EAPDP) se presentarán ordenados en función de estas seis subescalas.

\subsection{Análisis y presentación de datos}

Se efectuaron análisis descriptivos univariados (medias, porcentajes, frecuencias y desviaciones estándares) pormenorizados por a) Escala General, b) subescalas e c) ítems.

En las primeras cinco subescalas presentadas, la respuesta Muy de Acuerdo (M.A.=1) o De Acuerdo (A.=2) ante el ítem indica que el sujeto no adhiere al principio, puesto que conceptualmente estos reactivos se han medido en sentido contrario ${ }^{39}$. Ni de Acuerdo, Ni en Desacuerdo (N.A.D.=3) indica postura indiferente (valor de centro), mientras que la respuesta En Desacuerdo (D.=4) o Muy en Desacuerdo (M.D.=5) ante el ítem indica adhesión al principio. En la Subescala 6 los conceptos de los ítems fueron medidos en sentido positivo, por lo que el acuerdo con el ítem indica adhesión al principio y el desacuerdo indica falta de apoyo.

Teóricamente, estimamos que la categoría intermedia ( $\mathrm{Ni}$ de Acuerdo, $\mathrm{Ni}$ en Desacuerdo) debiese interpretarse como una baja adhesión, ya que, en términos kantianos, los principios penales, bajo la lógica del imperativo categórico, presentarían un carácter estricto en lo referente a su exigencia de universalidad ${ }^{40} \mathrm{o}$, al menos, generalidad. Así, ésta no sería una clara respuesta de apoyo. Por ello, aunque estamos abiertos a otras posibles interpretaciones,

39 Si bien conceptualmente los principios han sido medidos en sentido contrario, los ítems se encuentran redactados en sentido positivo e inverso. Esto no debería revestir problemas metodológicos de sub o sobreestimación en adhesión, ya que la aquiescencia (sesgo por respuesta automática) se evita mediante el sentido de la redacción y no del concepto. Adicionalmente, se aplicó la prueba de comparación de grupos extremos que permite asegurar variabilidad en las respuestas, permitiendo que éstas discriminen entre quienes apoyan y rechazan los principios, evitando concentraciones de respuesta en un solo sentido. Ver FUENTEALBA/BARRIGA, "Primera aproximación” cit. nota 36. Finalmente (como veremos en los siguientes resultados), se encontraron niveles globales de adhesión positiva en escalas con ítems negativos e, inversamente, rechazo a los principios en escalas con ítems positivos. Todo esto haría presumir que el sentido de los ítems no debería estar afectando el resultado, pero que es un aspecto que debiese considerarse en futuros estudios.

${ }^{40}$ KANT, Immanuel, Principios Metafísicos del Derecho, Madrid: Librería Victoriano Suárez Jacometrezo, 2012; KANT, Immanuel, Fundamentación para una Metafísica de las costumbres, Madrid: Ed. Alianza, 2012. 
Polít. crim. Vol. 13, № 25 (Julio 2018) Art. 7, pp. 233-263.

[http://www.politicacriminal.cl/Vol_13/n_25/Vol13N25A7.pdf]

aquí estimamos que el apoyo a los principios debe considerar únicamente las respuestas "De Acuerdo" o "Muy de Acuerdo" como indicadores de consenso. Para todas las subescalas, promedios próximos a 5.00 indican alta adhesión, cercanos a 1.00 indican baja adhesión y 3.00 indican un centro teórico.

\section{Resultados}

A continuación, presentamos los resultados comentados brevemente. La discusión de éstos se efectuará de forma integrada con las conclusiones, ya que muchos puntos de la discusión se verían repetidos si se presentaban en el mismo análisis de las tablas (eran redundantes) y/o implicaba una extensión del artículo el incorporarlas en un acápite separado.

\subsection{Nivel de adhesión a los principios del derecho penal: subescalas y escala general de APDP.}

La Tabla 1 resume los resultados descriptivos de las seis subescalas y de la Escala General de adhesión. Se presentan en términos de "Adhesión Muy baja", "Baja", "Ni alta ni baja (indiferente)", "Alta" y "Muy alta" en torno a los principios. Este resultado es fundamental para establecer la medida (o nivel) de adhesión a los principios penales.

Tabla 1

Nivel de adhesión a los principios del derecho penal y procesal penal. Descriptivos generales.

\begin{tabular}{|c|c|c|c|c|c|c|c|}
\hline Subescalas & $\begin{array}{l}\text { Muy } \\
\text { Baja }\end{array}$ & Baja & $\begin{array}{l}\text { Ni Alta, } \\
\text { Ni Baja }\end{array}$ & Alta & Muy Alta & Media & $D E$ \\
\hline $\begin{array}{l}\text { Adhesión al principio de gradualidad de } \\
\text { la pena }\end{array}$ & $26,9 \%$ & $27,7 \%$ & $13,8 \%$ & $22,8 \%$ & $8,7 \%$ & 2,59 & 0,93 \\
\hline $\begin{array}{l}\text { Adhesión al derecho al debido proceso y } \\
\text { personalidad de la pena }\end{array}$ & $9,0 \%$ & $18,4 \%$ & $17,1 \%$ & $32,4 \%$ & $23,0 \%$ & 3,40 & 0,68 \\
\hline $\begin{array}{l}\text { Adhesión al principio de intervención } \\
\text { mínima y legalidad en la aplicación de } \\
\text { penas y medidas }\end{array}$ & $32,9 \%$ & $33,2 \%$ & $15,2 \%$ & $12,2 \%$ & $6,4 \%$ & 2,26 & 0,69 \\
\hline $\begin{array}{l}\text { Adhesión al principio de humanidad de } \\
\text { las penas desde un sistema estatal de } \\
\text { justicia }\end{array}$ & $10,8 \%$ & $18,6 \%$ & $17,9 \%$ & $30,8 \%$ & $21,8 \%$ & 3,34 & 0,88 \\
\hline Adhesión al principio de legalidad penal & $21,9 \%$ & $30,9 \%$ & $15,9 \%$ & $20,1 \%$ & $11,1 \%$ & 2,68 & 0,94 \\
\hline $\begin{array}{l}\text { Adhesión a los derechos sociales y de } \\
\text { trato a los condenados y acusados }\end{array}$ & $13,2 \%$ & $18,8 \%$ & $20,2 \%$ & $29,1 \%$ & $18,7 \%$ & 3,24 & 0,80 \\
\hline Totales Escala General de adhesión & $18,8 \%$ & $24,3 \%$ & $16,6 \%$ & $25,0 \%$ & $15,4 \%$ & 2,92 & 0,55 \\
\hline
\end{tabular}

El análisis de la Tabla 1 muestra que las respuestas tienden a distribuirse polarmente más que a concentrarse en el centro. Esto indicaría que la mayor parte de los entrevistados no tendría una postura ambigua frente a los principios penales, sino que bastante definida (ya sea apoyo o rechazo). Por otra parte, -como se mostrará en las tablas siguientes ( $\mathrm{N}^{\mathrm{o}} 2$ a 7), a nivel descriptivo, no se observan diferencias importantes en el apoyo a los principios cuando éste se compara de acuerdo al tipo de delito consultado. Así, si agrupamos las respuestas de apoyo (Muy en desacuerdo o Desacuerdo) o rechazo (Muy de acuerdo, De acuerdo y, Ni de acuerdo Ni en desacuerdo) y las comparamos por cada par de ítems (de acuerdo a su nivel de rechazo social), no se observan diferencias importantes. Además, a nivel descriptivo, si bien se encuentran algunas diferencias al comparar los promedios entre cada par de ítems, éstas tienden a ser bastante leves. Esto indicaría que el apoyo o rechazo a los principios penales, no varía mucho de acuerdo al nivel de delito consultado (alto o bajo rechazo social), pero si 
FUENTEALBA, Pablo; LARRAÍN, Beatriz; BARRIGA, Omar. “ ¿Adhiere la ciudadanía a los principios del derecho penal y procesal penal? El caso del Gran Concepción, Chile”.

presenta cierta variación en la intensidad ${ }^{41}$. Dado que este patrón tiende a ser reiterativo, este hallazgo no será comentado en el análisis de las subescalas siguientes para evitar redundancia.

En lo que respecta a los niveles de consenso en torno a los principios penales, encontramos que los resultados varían dependiendo de la dimensión estudiada. De esta forma, si consideramos las subescalas con mayor apoyo, sólo dos de ellas presentan una adhesión sobre $50 \%$ (considerando los niveles Alto y Muy Alto). Así, un 55,4\% apoya el "derecho al debido proceso y personalidad de la pena" y un 52,6\% apoya el "principio de humanidad de las penas desde un sistema estatal de justicia". Aunque estas dimensiones son las que reflejan mejores niveles de consenso, es difícil afirmar que los valores sean muy altos, ya que sólo implicarían un apoyo moderado.

En las subescalas con menores niveles de apoyo encontramos que cuatro dimensiones presentan niveles de apoyo bajo el 50\% (considerando los niveles de apoyo Alto y Muy Alto, bajo esta cifra). De este modo, sólo un 31,5\% acepta el "principio de gradualidad de la pena". Apenas un 18,6\% adhiere al "principio de intervención mínima y legalidad en la aplicación de penas y medidas". Solamente un 30,2\% apoya el "principio de legalidad penal". Finalmente, un $47,8 \%$ apoya los "derechos sociales y de trato a condenados y acusados". Estas cifras muestran que el grado de consenso en torno a los principios es, en general, bajo y que habría más bien un disenso en la opinión pública.

La Escala General de adhesión (última fila) confirma el sentido de los resultados anteriores. Se observa que sólo un 40,4\% adhiere a los principios penales, un 16,6\% presenta una postura indiferente, mientras que un $43,1 \%$ no los acepta. El porcentaje de quienes adhieren es inferior al $50 \%$ de la población y, además, quienes aceptan los principios son menos que quienes los rechazan (incluso sin considerar la posición intermedia). De este modo, las cifras confirman el disenso en torno a los principios penales con los consecuentes problemas que esto implica en términos de legitimidad social para el orden jurídico. A continuación, presentamos los resultados pormenorizadamente.

\subsection{Nivel de adhesión al principio de gradualidad de la pena.}

La subescala de Adhesión al principio de gradualidad de la pena mide el consenso en torno a la idea de que las penas deben aplicarse de forma diferenciada, utilizando criterios de graduación (o proporción) relativos a los elementos esenciales del delito (como la culpabilidad y responsabilidad, que distingue entre dolo o culpa), así como elementos accidentales (vinculados a las atenuantes, tales como irreprochable conducta anterior, responsabilidad penal especial en trato diferenciado entre adultos y menores, reparación del daño causado, esfuerzo personal del acusado). La variable no mide proporcionalidad entendida como relación de proporción entre la sanción y el valor del bien jurídico afectado.

\footnotetext{
${ }^{41}$ Debe advertirse que para comparar los resultados de acuerdo a los niveles de rechazo social del delito en esta subescala, así como en las subescalas subsiguientes, no se realizaron pruebas de hipótesis, y sólo se analizarán diferencias a nivel descriptivo. En otra publicación realizaremos las comparaciones recurriendo al uso de los test de hipótesis correspondientes.
} 
Polit. crim. Vol. 13, № 25 (Julio 2018) Art. 7, pp. 233-263.

[http://www.politicacriminal.cl/Vol_13/n_25/Vol13N25A7.pdf]

Tabla 2

Descriptivos para Adhesión al principio de gradualidad de la pena.

\begin{tabular}{|c|c|c|c|c|c|c|c|}
\hline Ítems & M.A. & A. & N.A.D. & $D$. & M.D. & $M$ & $D E$ \\
\hline $\begin{array}{l}\text { 43.-Considero que ante delitos como el homicidio, la pedofilia o la } \\
\text { violación, un adolescente de entre 14-17 años tiene la misma } \\
\text { responsabilidad que un adulto y debería recibir el mismo tipo de } \\
\text { castigo. }\end{array}$ & $45,3 \%$ & $28,2 \%$ & $8,9 \%$ & $11,4 \%$ & $6,2 \%$ & 2,05 & 1,25 \\
\hline $\begin{array}{l}\text { 47.-Considero que ante delitos como robo sin violencia, cuento del } \\
\text { tío, estafa telefónica, mecheo, un adolescente de entre } 14-17 \text { años } \\
\text { tiene la misma responsabilidad que un adulto y debería recibir el } \\
\text { mismo tipo de castigo. }\end{array}$ & $39,6 \%$ & $32 \%$ & $8,9 \%$ & $12,7 \%$ & $6,8 \%$ & 2,15 & 1,26 \\
\hline $\begin{array}{l}\text { 44.-Considero que ante delitos como el homicidio, la pedofilia o la } \\
\text { violación, alguien que actuó intencionalmente tiene la misma } \\
\text { responsabilidad que alguien que actuó sin la intención (porque fue } \\
\text { imprudente, o por ignorancia) y debería recibir el mismo castigo. }\end{array}$ & $21,4 \%$ & $30,6 \%$ & $14,9 \%$ & $23,3 \%$ & $9,8 \%$ & 2,69 & 1,30 \\
\hline $\begin{array}{l}\text { 48.-Considero que ante delitos como robo sin violencia, cuento del } \\
\text { tío, estafa telefónica, mecheo, alguien que actuó intencionalmente } \\
\text { tiene la misma responsabilidad que alguien que actuó sin la } \\
\text { intención (porque fue imprudente, o por ignorancia) y debería } \\
\text { recibir el mismo castigo. }\end{array}$ & $24,1 \%$ & $30,1 \%$ & $16 \%$ & $23,3 \%$ & $6,5 \%$ & 2,58 & 1,26 \\
\hline $\begin{array}{l}\text { 45.-Considero que ante delitos como el homicidio, la pedofilia o la } \\
\text { violación, se deben aplicar castigos a todos por igual, sin diferenciar } \\
\text { entre alguien que tiene un historial criminal manchado y alguien } \\
\text { con sus antecedentes limpios. }\end{array}$ & $24,7 \%$ & $22 \%$ & $11,7 \%$ & $28,2 \%$ & $13,6 \%$ & 2,84 & 1,42 \\
\hline $\begin{array}{l}\text { 49.-Considero que ante delitos como robo sin violencia, cuento del } \\
\text { tío, estafa telefónica, mecheo, se deben aplicar castigos a todos por } \\
\text { igual, sin diferenciar entre alguien que tiene un historial criminal } \\
\text { manchado y alguien con sus antecedentes limpios. }\end{array}$ & $23 \%$ & $25,2 \%$ & $13,8 \%$ & $29,3 \%$ & $8,7 \%$ & 2,75 & 1,33 \\
\hline $\begin{array}{l}\text { 46.-Considero que ante delitos como el homicidio, la pedofilia o la } \\
\text { violación, se debe juzgar o aplicar castigos a todos por igual, sin } \\
\text { diferenciar si el delincuente realizó acciones positivas que pueden } \\
\text { favorecerlo (por ejemplo, ayudó a la víctima, se entregó a la policía, } \\
\text { colaboró con la justicia, intentó reparar el daño causado, etc.) }\end{array}$ & $19,8 \%$ & $25,7 \%$ & $18,7 \%$ & $27,4 \%$ & $8,4 \%$ & 2,79 & 1,27 \\
\hline $\begin{array}{l}\text { 50.-Considero que ante delitos como robo sin violencia, cuento del } \\
\text { tío, estafa telefónica, mecheo, se debe juzgar o aplicar castigos a } \\
\text { todos por igual, sin diferenciar si el delincuente realizó acciones } \\
\text { positivas que pueden favorecerlo (por ejemplo, ayudó a la víctima, } \\
\text { se entregó a la policía, colaboró con la justicia, intentó reparar el } \\
\text { daño causado, etc.) }\end{array}$ & $17,6 \%$ & $27,6 \%$ & $17,9 \%$ & $26,8 \%$ & $10 \%$ & 2,84 & 1,28 \\
\hline Totales (subescala 1) & $26,9 \%$ & $27,7 \%$ & $13,8 \%$ & $22,8 \%$ & $8,7 \%$ & 2,59 & 0,93 \\
\hline
\end{tabular}

La Tabla 2 muestra que la mayor parte de los entrevistados $(68,4 \%)$ no acepta el principio de gradualidad de la pena, lo cual reflejaría bajos niveles de consenso en torno a la noción de proporcionalidad. Al no aceptar dicho principio, se podría pensar que la población prefiere un sistema penal indiferenciado que no establezca distinciones al momento de aplicar las sanciones y que no distinga niveles de responsabilidad. El que los sujetos no adhieran y/o no comprendan la lógica de la graduación penal permitiría explicar el hecho de que la ciudadanía manifieste cierta insatisfacción con el sistema de sanciones, ya que no se corresponderían con sus expectativas punitivas. Esto también explicaría la demanda ciudadana por el aumento de las sanciones, que exige que se eliminen atenuantes, las que son concebidas como beneficios o privilegios para los delincuentes (bajo la posible creencia de que reducen el efecto disuasivo de la pena).

\subsection{Nivel de adhesión al derecho al debido proceso y personalidad de la pena.}

La subescala de Adhesión del derecho al debido proceso y personalidad de la pena permite conocer el consenso en torno al principio que establece que en el juicio deben respetarse ciertas garantías de los acusados, tales como el derecho a defensa, a jueces independientes e imparciales y el respeto a la legalidad en el proceso probatorio. Además, una vez concluido el 
FUENTEALBA, Pablo; LARRAÍN, Beatriz; BARRIGA, Omar. “ ¿Adhiere la ciudadanía a los principios del derecho penal y procesal penal? El caso del Gran Concepción, Chile”.

proceso, la responsabilidad penal es personal, sin que la pena deba trascender del sujeto que cometió el delito ${ }^{42}$.

Tabla 3

Descriptivos para Adhesión al derecho al debido proceso y personalidad de la pena.

\begin{tabular}{|c|c|c|c|c|c|c|c|}
\hline Ítems & M.A. & $A$. & N.A.D. & D. & M.D. & $M$ & $D E$ \\
\hline $\begin{array}{l}\text { 3.-Cuando finaliza un juicio por homicidio, violación o pedofilia, } \\
\text { los jueces deberían castigar a un acusado cuando hay más } \\
\text { probabilidades de que sea culpable, aunque puedan existir ciertas } \\
\text { dudas fundadas de que tal vez no cometió el delito. }\end{array}$ & $16,1 \%$ & $27,2 \%$ & $23,7 \%$ & $22,9 \%$ & $10,1 \%$ & 2,84 & 1,24 \\
\hline $\begin{array}{l}\text { 31.-Cuando finaliza un juicio por robo sin violencia, mecheo, } \\
\text { lanzazo o cuento del tío, los jueces deberían castigar a un acusado } \\
\text { cuando hay más probabilidades de que sea culpable, aunque puedan } \\
\text { existir ciertas dudas fundadas de que tal vez no cometió el delito. }\end{array}$ & $8,4 \%$ & $29,3 \%$ & $26,9 \%$ & 26,9 & $8,4 \%$ & 2,98 & 1,11 \\
\hline $\begin{array}{l}\text { 4.-En los juicios por robo sin violencia, mecheo, cuento del tío o } \\
\text { lanzazos, los jueces deberían estar del lado de quienes acusan al } \\
\text { sospechoso para que ganen el juicio, en vez de ser objetivos y } \\
\text { neutrales. }\end{array}$ & $12,2 \%$ & $16,8 \%$ & $16,8 \%$ & $33,9 \%$ & $20,3 \%$ & 3,33 & 1,30 \\
\hline $\begin{array}{l}\text { 18.-En los juicios por homicidio, pedofilia o violación, los jueces } \\
\text { deberían estar del lado de quienes acusan al sospechoso para que } \\
\text { ganen el juicio, en vez de ser objetivos y neutrales. }\end{array}$ & $8,9 \%$ & $13,6 \%$ & $17,6 \%$ & $34,4 \%$ & $25,5 \%$ & 3,54 & 1,25 \\
\hline $\begin{array}{l}\text { 8.-Apoyaría el uso de medios ilegales (por ejemplo, escuchas no } \\
\text { autorizadas, pruebas y testigos falsos, confesiones forzadas, etc.) en } \\
\text { un juicio si permiten que se castigue a un acusado por robo sin } \\
\text { violencia, lanzazo, mecheo o cuento del tío. }\end{array}$ & $5,1 \%$ & 11,4 & $14,9 \%$ & $36,3 \%$ & $32,2 \%$ & 3,79 & 1,16 \\
\hline $\begin{array}{l}\text { 23.-Apoyaría el uso de medios ilegales (por ejemplo, escuchas no } \\
\text { autorizadas, pruebas y testigos falsos, confesiones forzadas, etc.) en } \\
\text { un juicio si permiten que se castigue a un acusado por homicidio, } \\
\text { pedofilia o violación. }\end{array}$ & $9,2 \%$ & $15,7 \%$ & $16,3 \%$ & $34,7 \%$ & $24,1 \%$ & 3,49 & 1,27 \\
\hline $\begin{array}{l}\text { 9.-Los familiares más cercanos de quienes han cometido delitos de } \\
\text { violación, homicidio o pedofilia también deberían recibir algún } \\
\text { castigo, aunque sea menor. }\end{array}$ & $7 \%$ & $8,9 \%$ & $8,9 \%$ & $30,4 \%$ & $44,7 \%$ & 3,97 & 1,24 \\
\hline $\begin{array}{l}\text { 37.-Los familiares más cercanos de quienes han cometido delitos } \\
\text { de robo sin violencia, cuento del tío, mecheo, lanzazo, también } \\
\text { deberían recibir algún castigo, aunque sea menor. }\end{array}$ & $3,8 \%$ & $10,1 \%$ & $7,9 \%$ & $38,9 \%$ & $39,4 \%$ & 4,00 & 1,11 \\
\hline $\begin{array}{l}\text { 11.-Los acusados por robo sin violencia, lanzazo, mecheo o cuento } \\
\text { del tío, deberían perder el derecho a defenderse en un juicio para } \\
\text { ser escuchados y exponer sus argumentos y pruebas. }\end{array}$ & $5,7 \%$ & $11,4 \%$ & $17,1 \%$ & $45,5 \%$ & $20,3 \%$ & 3,63 & 1,10 \\
\hline $\begin{array}{l}\text { 34.-Los acusados por violación, homicidio o pedofilia, deberían } \\
\text { perder el derecho a defenderse en un juicio para ser escuchados y } \\
\text { exponer sus argumentos y pruebas. }\end{array}$ & $10,9 \%$ & $19,1 \%$ & $22,9 \%$ & $31,9 \%$ & $16,1 \%$ & 3,22 & 1,24 \\
\hline $\begin{array}{l}\text { 17.-Ante delitos como el robo sin violencia, mecheo, lanzazo o } \\
\text { cuento del tío, las autoridades deberían intervenir en las decisiones } \\
\text { de los jueces para que condenen a los acusados o aumenten sus } \\
\text { castigos. }\end{array}$ & $10,4 \%$ & $26,5 \%$ & $19,9 \%$ & $24,9 \%$ & $18,3 \%$ & 3,14 & 1,28 \\
\hline $\begin{array}{l}\text { 32.-Ante delitos como homicidio, pedofilia o violación, las } \\
\text { autoridades deberían influir en las decisiones de los jueces para que } \\
\text { condenen a los acusados o aumenten sus castigos. }\end{array}$ & $18,9 \%$ & $29,6 \%$ & $11,4 \%$ & $25,8 \%$ & $14,4 \%$ & 2,88 & 1,37 \\
\hline Totales (subescala 2) & $9,0 \%$ & $18,4 \%$ & $17,1 \%$ & $32,4 \%$ & $23,0 \%$ & 3,40 & 0,68 \\
\hline
\end{tabular}

Los datos de la Tabla 3 muestran que la mayor parte de los sujetos $(55,4 \%)$ estima que, en un juicio, deben respetarse las garantías básicas del derecho al debido proceso. Sin embargo, debe precisarse que una fracción importante de los individuos no aceptaría la existencia de garantías procesales básicas en lo penal. Esto explicaría por qué una porción significativa de la ciudadanía espera que los acusados o sospechosos sean condenados rápidamente, sin mayor rigor procesal, muchas veces cuestionando el rol (o actitud) de imparcialidad de los jueces (bajo la creencia de que éstos muchas veces buscan favorecer a los delincuentes) y/o por qué

${ }^{42}$ Cuando se publicaron las propiedades métricas de la escala, los autores repararon en el hecho de que la presencia del reactivo que mide adhesión a la personalidad de la pena en la subescala de Adhesión al Debido Proceso (ítem 9 y 37) presentaba cierta incoherencia desde el punto de vista teórico. Por ello, este aspecto debería considerarse en futuras evaluaciones del instrumento. Ver FUENTEALBA/BARRIGA, "Primera aproximación", cit. nota 35. 
Polít. crim. Vol. 13, N 25 (Julio 2018) Art. 7, pp. 233-263.

[http://www.politicacriminal.cl/Vol_13/n_25/Vol13N25A7.pdf]

la opinión pública asume la culpabilidad de los imputados sin que, previamente, exista una sentencia derivada de un adecuado proceso.

\subsection{Nivel de adhesión al principio de intervención mínima y legalidad en la aplicación de penas y medidas.}

La subescala de Adhesión al principio de intervención mínima y legalidad en la aplicación de medidas y penas permite conocer el consenso en torno al principio que establece que debe respetarse el rigor legal en la aplicación de medidas cautelares (y por oposición a la presunción de inocencia) y de seguridad (principio de peligrosidad) y, por ello, se relaciona con el principio de necesidad y habeas corpus. El rigor legal se establece por la presencia de los ítems 10 y 20, los que se encuentran vinculados con el debido proceso (imparcialidad e independencia) y con el rigor y estándar probatorio. Finalmente, la presencia de los ítems 14 y 40, que miden "subsidiariedad sancionatoria", permite inferir que la población interpreta las medidas cautelares y de seguridad como sanciones penales en sentido estricto.

\section{Tabla 4}

Descriptivos para Adhesión al principio

de intervención mínima y legalidad en la aplicación de penas y medidas.

\begin{tabular}{|c|c|c|c|c|c|c|c|}
\hline Ítems & M.A. & $A$. & N.A.D. & $D$. & M.D. & $M$ & $D E$ \\
\hline $\begin{array}{l}\text { 10.-Si los noticiarios o los periódicos presentan antecedentes que } \\
\text { mostrarían que un sospechoso es responsable de un delito de } \\
\text { violación, homicidio o pedofilia, los jueces deberían considerar esta } \\
\text { información para tomar su decisión. }\end{array}$ & $24 \%$ & $34,3 \%$ & $17,4 \%$ & $16,9 \%$ & $7,4 \%$ & 2,49 & 1,23 \\
\hline $\begin{array}{l}\text { 20.-Si los noticiarios o los periódicos presentan antecedentes que } \\
\text { mostrarían que un sospechoso es responsable de un delito de robo sin } \\
\text { violencia, cuento del tío, lanzazo o mecheo, los jueces deberían } \\
\text { considerar esta información para tomar su decisión. }\end{array}$ & $20,1 \%$ & $39,3 \%$ & $18,7 \%$ & $13,8 \%$ & $8,1 \%$ & 2,51 & 1,19 \\
\hline $\begin{array}{l}\text { 15.-Aunque las primeras pruebas que vinculan a un sospechoso con } \\
\text { un delito de robo sin violencia, lanzazo, mecheo o cuento del tío, sean } \\
\text { insuficientes o contradictorias, el juez debería dejarlo preso mientras } \\
\text { se realiza la investigación que busca definir si es responsable. }\end{array}$ & $27,6 \%$ & $37,7 \%$ & $17,9 \%$ & $11,7 \%$ & $5,1 \%$ & 2,29 & 1,14 \\
\hline $\begin{array}{l}\text { 30.-Aunque las primeras pruebas que vinculan a un sospechoso con } \\
\text { un delito de homicidio, pedofilia o violación, sean insuficientes o } \\
\text { contradictorias, el juez debería dejarlo preso mientras se realiza la } \\
\text { investigación que busca definir si es responsable. }\end{array}$ & $27,9 \%$ & $41,5 \%$ & $13,8 \%$ & $11,9 \%$ & $4,9 \%$ & 2,29 & 2,24 \\
\hline $\begin{array}{l}\text { 27.- } \mathrm{Si} \text { una persona está por terminar su encarcelamiento por } \\
\text { violación, homicidio o pedofilia, deberían aplicarle medidas de } \\
\text { control y vigilancia de por vida. }\end{array}$ & $45,8 \%$ & $29,3 \%$ & $10 \%$ & $8,7 \%$ & $6,2 \%$ & 2,00 & 1,67 \\
\hline $\begin{array}{l}\text { 13.-Si una persona está por terminar su encarcelamiento por robo sin } \\
\text { violencia, lanzazo, cuento del tío o mecheo, deberían aplicarle } \\
\text { medidas de control y vigilancia de por vida. }\end{array}$ & $22,2 \%$ & $24,9 \%$ & $25,5 \%$ & 20,9 & $6,5 \%$ & 2,64 & 1,22 \\
\hline $\begin{array}{l}\text { 14.-Ante delitos como homicidio, pedofilia o violación, deberían } \\
\text { aplicarse castigos más drásticos aumentándose las penas. }\end{array}$ & $66 \%$ & $18,2 \%$ & $5,7 \%$ & $3 \%$ & $7,1 \%$ & 1,67 & 1,17 \\
\hline $\begin{array}{l}\text { 40.-Ante delitos como robo sin violencia, cuento del tío, lanzazo o } \\
\text { mecheo, deberían aplicarse castigos más drásticos aumentándose las } \\
\text { penas. }\end{array}$ & $29,4 \%$ & $40,9 \%$ & $12,8 \%$ & $10,9 \%$ & $6 \%$ & 2,23 & 1,16 \\
\hline Totales (subescala 3) & $32,9 \%$ & $33,2 \%$ & $15,2 \%$ & $12,2 \%$ & $6,4 \%$ & 2,26 & 0,69 \\
\hline
\end{tabular}

La Tabla 4 muestra que la mayor parte de la población entrevistada $(81,3 \%)$ no apoya los principios asociados a la limitación de penas y medidas. Esto implica que, posiblemente, considerarían que menores estándares de rigor procesal y/o probatorio (como los exhibidos algunas veces en el trabajo periodístico) resultarían suficientes para fundar una sentencia, lo cual reflejaría un bajo apoyo en torno al derecho al debido proceso en general. Adicionalmente, el apoyo hacia la aplicación de medidas cautelares más allá de la necesidad, 
FUENTEALBA, Pablo; LARRAÍN, Beatriz; BARRIGA, Omar. “ ¿Adhiere la ciudadanía a los principios del derecho penal y procesal penal? El caso del Gran Concepción, Chile”.

implica que una parte importante de la ciudadanía probablemente no infiere las consecuencias de éstas para la presunción de inocencia, considerando que deben aplicarse de manera preventiva o incluso como forma de sanción anticipada. Esto explicaría el descontento de la ciudadanía ante decisiones judiciales en las cuales los imputados no quedan afectos a medidas cautelares privativas de libertad, siendo estas decisiones interpretadas como formas de impunidad (lo que, además, implica presuponer la culpabilidad del imputado). Por su parte, el rechazo ante el principio de peligrosidad (de forma restringida), implica que una parte importante de los sujetos considera que las medidas de seguridad deben exceder la duración de la pena. Esto limita seriamente las posibilidades de reinserción en la sociedad de los condenados, puesto que se considera que un sujeto que ha sido condenado es considerado por los entrevistados siempre un sujeto potencialmente peligroso y que debe encontrarse bajo vigilancia.

\subsection{Nivel de adhesión al principio de humanidad de las penas desde un sistema estatal de justicia.}

La subescala de Adhesión al principio de humanidad de las penas desde un sistema estatal de justicia permite conocer el nivel de legitimidad ante el sistema estatal que concentra y monopoliza el ejercicio de la justicia, junto con las limitaciones básicas impuestas a la autoridad jurisdiccional para la administración del ius puniendi que establecen que las penas no pueden consistir en maltratos físicos, psicológicos, torturas ni tratos degradantes. Estas limitaciones se imponen tanto a nivel de penas legamente establecidas como a nivel de ejecución penal, prescribiéndose el respeto a estos derechos humanos de los condenados.

Tabla 5

Descriptivos para Adhesión al principio de humanidad de las penas desde un sistema estatal de justicia.

\begin{tabular}{|c|c|c|c|c|c|c|c|}
\hline Ítems & M.A. & $A$. & N.A.D. & D. & M.D. & $M$ & $D E$ \\
\hline $\begin{array}{l}\text { 12.-Para el robo sin violencia, lanzazo o cuento del tío, deberían } \\
\text { existir sanciones que, además de la cárcel, consistan en causarle daños } \\
\text { psicológicos o físicos al delincuente como golpes o palizas, que sean } \\
\text { acordes a los daños causados. }\end{array}$ & $6 \%$ & $12,5 \%$ & $11,4 \%$ & $38,2 \%$ & $32 \%$ & 3,78 & 1,19 \\
\hline $\begin{array}{l}\text { 25.-Para la violación, homicidio o pedofilia, deberían existir } \\
\text { sanciones que, además de la cárcel, consistan en causarle daños } \\
\text { psicológicos o físicos al criminal como golpes, palizas, castración a } \\
\text { los agresores sexuales, que sean acordes a los daños causados. }\end{array}$ & $17,9 \%$ & $26,8 \%$ & $13 \%$ & $24,4 \%$ & 17,9 & 2,98 & 1,40 \\
\hline $\begin{array}{l}\text { 22.-Si un preso por homicidio, violación o pedofilia, es golpeado o } \\
\text { maltratado por los gendarmes, es porque en cierta medida se lo } \\
\text { merece. }\end{array}$ & $12 \%$ & $20,9 \%$ & $21,2 \%$ & $30,2 \%$ & $15,8 \%$ & 3,17 & 1,26 \\
\hline $\begin{array}{l}\text { 39.-Si un preso por robo sin violencia, mecheo, lanzazo, cuento del } \\
\text { tío, es golpeado o maltratado por los gendarmes, es porque en cierta } \\
\text { medida se lo merece. }\end{array}$ & $12,5 \%$ & $14,4 \%$ & $24,8 \%$ & $32,2 \%$ & 16,1 & 3,25 & 1,25 \\
\hline $\begin{array}{l}\text { 24.-Ante delitos como robo sin violencia, mecheo, cuento del tío, las } \\
\text { víctimas o sus familias deberían poder tomarse la justicia por sus } \\
\text { propias manos. }\end{array}$ & $7 \%$ & $19,8 \%$ & $16,5 \%$ & $31,2 \%$ & $25,5 \%$ & 3,48 & 1,26 \\
\hline $\begin{array}{l}\text { 38.-Ante delitos de pedofilia, homicidio, violación, las víctimas o sus } \\
\text { familias deberían poder tomarse la justicia por sus propias manos. }\end{array}$ & $9,8 \%$ & $17,3 \%$ & $20,6 \%$ & $28,7 \%$ & $23,6 \%$ & 3,39 & 1,28 \\
\hline Totales (subescala 4) & $10,8 \%$ & $18,6 \%$ & $17,9 \%$ & $30,8 \%$ & $21,8 \%$ & 3,34 & 0,88 \\
\hline
\end{tabular}

La Tabla 5 muestra que, en lo que respecta al nivel de consenso global, si bien la mayor parte de los entrevistados adhiere al principio medido (52,6\%), este porcentaje supera levemente el $50 \%$. Esto implica que una fracción importante de los sujetos estudiados -y posiblemente de la ciudadanía en general- podría llegar a apoyar leyes penales que establezcan sanciones consistentes en torturas o maltratos físicos y psicológicos, así como tratos inhumanos hacia los reos en la ejecución penal. Una explicación plausible es que consideren que los condenados 
Polit. crim. Vol. 13, № 25 (Julio 2018) Art. 7, pp. 233-263.

[http://www.politicacriminal.cl/Vol_13/n_25/Vol13N25A7.pdf]

han perdido el derecho a exigir la protección de sus derechos humanos fundamentales (por ser enemigos de la sociedad, por haber quebrantado el pacto social u otros motivos) ${ }^{43}$.

Los sujetos que no aceptan el principio de humanidad de las penas tampoco aceptarían una idea propia del orden liberal moderno que concibe al Estado como órgano exclusivo en la administración de justicia con restricciones en el uso de violencia (principios de necesidad e intervención mínima). Una fracción importante de la población, tal vez, preferirían un sistema privado de justicia (basado en el principio vendetta) y sin restricciones. Este pensamiento sería característico de una cultura penal pre-moderna, basada en una concepción represiva de la pena y no restitutiva, ya que esta última comienza a aparecer en la medida que surge y se desarrolla el Estado como órgano diferenciado ${ }^{44}$. Por ello, en términos durkheimianos, la presencia de un derecho penal represivo antes que uno restitutivo podría denotar la persistencia de pensamientos y sentimientos de comunidad (solidaridad o cohesión mecánica), puesto que el colectivo, como unidad, se resentiría emocionalmente ante el crimen reaccionando de esta forma ${ }^{45}$.

Estos resultados podrían contribuir a comprender fenómenos tales como linchamientos, detenciones ciudadanas o la opinión pública ante el delito desde una nueva perspectiva.

\subsection{Nivel de adhesión al principio de legalidad penal.}

La subescala de Adhesión al principio de legalidad penal mide el nivel de consenso social en torno al principio que establece que delitos y penas deben encontrarse previamente establecidos por ley. Esto incluye la máxima taxatividad legal, que prescribe que la ley penal debe ser clara y precisa (versus las leyes en blanco), así como la máxima taxatividad interpretativa que reduce la arbitrariedad del juez al exigir apego al texto legal y mínima interpretación, salvo que sea favorable al acusado o reo. Adicionalmente, mide el principio de Reserva Legal, ya que, en lo penal, sólo puede considerarse la ley emanada del congreso y no la opinión pública que no se ha expresado por la vía establecida constitucionalmente.

\footnotetext{
${ }^{43}$ Un estudio cualitativo podría arrojar información sobre los motivos.

${ }^{44}$ DURKHEIM, Émile, La división del trabajo social, Madrid: Ed. Akal, 1982, passim.

${ }^{45}$ DURKHEIM, La división, cit. nota 44.
} 
FUENTEALBA, Pablo; LARRAÍN, Beatriz; BARRIGA, Omar. “ ¿Adhiere la ciudadanía a los principios del derecho penal y procesal penal? El caso del Gran Concepción, Chile”.

Tabla 6

Descriptivos para Adhesión al principio de legalidad penal.

\begin{tabular}{|c|c|c|c|c|c|c|c|}
\hline Ítems & M.A. & $A$. & N.A.D. & $D$. & M.D. & $M$ & $D E$ \\
\hline $\begin{array}{l}\text { 6.-Si la pena máxima que establece la ley para un robo sin violencia, } \\
\text { hurto, mecheo, cuento del tío o lanzazo es considerada baja por la } \\
\text { mayoría de la gente, los jueces deberían aplicar un castigo más alto } \\
\text { aunque signifique salirse de la ley. }\end{array}$ & $23 \%$ & $32 \%$ & $14,6 \%$ & $19,2 \%$ & $10,3 \%$ & 2,61 & 1,31 \\
\hline $\begin{array}{l}\text { 19.-Si la pena máxima que establece la ley para una violación, } \\
\text { homicidio o pedofilia, es considerada baja por la mayoría de la } \\
\text { gente, los jueces deberían aplicar un castigo más alto aunque } \\
\text { signifique salirse de la ley. }\end{array}$ & $32 \%$ & $24,1 \%$ & $12,5 \%$ & $18,4 \%$ & $13 \%$ & 2,56 & 1,43 \\
\hline $\begin{array}{l}\text { 21.-Si la pena máxima que establece la ley para un robo sin } \\
\text { violencia, mecheo, cuento del tío o lanzazo es considerada baja por } \\
\text { los jueces del caso, deberían aplicar un castigo más alto aunque } \\
\text { signifique salirse de la ley. }\end{array}$ & $15,4 \%$ & $31,4 \%$ & $17,9 \%$ & $23,8 \%$ & $11,4 \%$ & 2,84 & 1,27 \\
\hline $\begin{array}{l}\text { 36.-Si la pena máxima que establece la ley para una violación, } \\
\text { homicidio o pedofilia, es considerada baja por los jueces del caso, } \\
\text { deberían aplicar un castigo más alto aunque signifique salirse de la } \\
\text { ley. }\end{array}$ & $24,5 \%$ & $22,6 \%$ & $11,7 \%$ & $25,8 \%$ & $15,5 \%$ & 2,85 & 1,44 \\
\hline $\begin{array}{l}\text { 7.-En vez de ser tan precisas y detalladas las leyes para definir } \\
\text { delitos como violación, homicidio o pedofilia, deberían ser más } \\
\text { generales y flexibles para poder castigar a todo el que tenga } \\
\text { conductas parecidas. }\end{array}$ & $19,3 \%$ & $37,8 \%$ & $16,8 \%$ & $17,4 \%$ & $8,7 \%$ & 2,58 & 1,23 \\
\hline $\begin{array}{l}\text { 35.-En vez de ser tan precisas y detalladas las leyes para definir } \\
\text { delitos como lanzazo, mecheo, cuento del tío, deberían ser más } \\
\text { generales y flexibles para poder castigar a todo el que tenga } \\
\text { conductas parecidas. }\end{array}$ & $17,4 \%$ & $36,7 \%$ & $22 \%$ & $16 \%$ & $7,9 \%$ & 2,60 & 1,18 \\
\hline Totales (subescala 5) & $21,9 \%$ & $30,9 \%$ & $15,9 \%$ & $20,1 \%$ & $11,1 \%$ & 2,68 & 0,94 \\
\hline
\end{tabular}

Los datos expuestos en la Tabla 6 muestran un bajo consenso en torno al principio de legalidad $(31,2 \%)$. De esta forma, la cultura ciudadana se adosaría a una concepción más flexible (incluso ambigua) del derecho en lo penal y procesal penal que permitiese mayores márgenes de interpretación de la ley y que posibilite la aplicación de penas que eventualmente pudiesen exceder considerablemente el texto legal. Entonces, se revelaría un disenso en torno a los principios de máxima taxatividad (legal e interpretativa) e irretroactividad penal ${ }^{46}$, apoyándose incluso las leyes en blanco. Adicionalmente, los resultados podrían denotar una forma de interpretar la administración de justicia en términos de una democracia directa, ya que los entrevistados podrían esperar que los jueces (o tribunales) decidan en función de las opiniones sociales (que supuestamente expresarían la voluntad ciudadana) y no a través de la ley debidamente promulgada. Esto revelaría que la cultura ciudadana tampoco apoya plenamente (o no comprende el sentido) del principio de reserva legal, así como el rol del juez ante la ley.

Respecto al nivel de consenso, los resultados obtenidos en esta escala ayudan a comprender el descontento de una parte importante de la población con la función judicial. La ciudadanía interpretaría que muchas de las decisiones judiciales constituirían formas de usurpación de la voluntad soberana por parte de los jueces al momento de administrar justicia ya que, aunque estas decisiones se ajusten a la legalidad procesal y penal, no se corresponderían con la opinión pública en su manifestación espontánea e inmediata.

\footnotetext{
${ }^{46} \mathrm{Si}$ bien la irretroactividad penal no ha sido medida explícitamente (y se sugiere su incorporación en nuevas mediciones), se encuentra en cierta medida implícitamente como principio en los reactivos usados, ya que cualquier interpretación o sanción a posteriori, no consignada en la ley, presupondría una transgresión a esta idea.
} 
Polít. crim. Vol. 13, N 25 (Julio 2018) Art. 7, pp. 233-263.

[http://www.politicacriminal.cl/Vol_13/n_25/Vol13N25A7.pdf]

\subsection{Nivel de adhesión a los derechos sociales y de trato a condenados y acusados.}

La subescala de Adhesión a los derechos sociales y de trato a condenados y acusados permite medir la adhesión hacia una dimensión práctica de los principios penales. Se entendería como una acción ejercida desde el Estado (en su dimensión jurisdiccional) hacia acusados y condenados, que podrían presuponer gastos sociales en programas y políticas públicas, pero que constituye una consecuencia cuasi necesaria de los principios penales a nivel teórico. Esta dimensión práctica se expresaría en la adhesión al derecho a defensa técnica, a ciertos derechos sociales en materia penitenciaria (condiciones dignas desde el punto de vista penitenciario) y presunción de inocencia (no sólo que se "considere" o "presuma" como inocente, sino que se "trate" como tal) ${ }^{47}$. De esta forma, este aspecto constituye una extensión desde el Estado de derecho hacia el Estado social de derecho ${ }^{48}$.

\section{Tabla 7}

Adhesión a los derechos sociales y de trato a condenados y acusados.

\begin{tabular}{|c|c|c|c|c|c|c|c|}
\hline Ítems & M.A. & A. & N.A.D. & $D$. & M.D. & $M$ & $D E$ \\
\hline $\begin{array}{l}\text { 1.-Un sospechoso por homicidio, pedofilia o violación, debe } \\
\text { tratarse como inocente por la justicia mientras un tribunal no lo } \\
\text { declare culpable. }\end{array}$ & $16,8 \%$ & $29,3 \%$ & $12,7 \%$ & $19,2 \%$ & $22 \%$ & 3,00 & 1,43 \\
\hline $\begin{array}{l}\text { 29.-Un sospechoso por robo sin violencia, mecheo, lanzazo o } \\
\text { cuento del tío, debe tratarse como inocente por la justicia mientras } \\
\text { un tribunal no declare que es culpable. }\end{array}$ & $14,9 \%$ & $32 \%$ & $27,9 \%$ & $17,6 \%$ & $7,6 \%$ & 3,29 & 1,15 \\
\hline $\begin{array}{l}\text { 5.-Si un acusado por homicidio, pedofilia o violación, no tiene } \\
\text { recursos, el Estado debería asignarle un abogado y medios para que } \\
\text { se defienda de forma gratuita. }\end{array}$ & $24,4 \%$ & $31,4 \%$ & $10,3 \%$ & $16,3 \%$ & $17,6 \%$ & 3,29 & 1,44 \\
\hline $\begin{array}{l}\text { 33.-Si un acusado por robo sin violencia, lanzazo, mecheo o cuento } \\
\text { del tío, no tiene recursos, el Estado debería asignarle un abogado y } \\
\text { medios para que se defienda de forma gratuita. }\end{array}$ & $20,7 \%$ & $33,4 \%$ & $19 \%$ & $17,9 \%$ & $9 \%$ & 3,39 & 1,25 \\
\hline $\begin{array}{l}\text { 26.-A los condenados por delitos como robo sin violencia, cuento } \\
\text { del tío o mecheo, deberían mantenerlos en condiciones dignas } \\
\text { dentro de la cárcel, respetándoles sus derechos como seres } \\
\text { humanos. }\end{array}$ & $20,4 \%$ & $31,3 \%$ & $24,7 \%$ & $15,8 \%$ & $7,9 \%$ & 3,40 & 1,20 \\
\hline $\begin{array}{l}\text { 42.-A los condenados por delitos de homicidio, pedofilia o } \\
\text { violación, deberían mantenerlos en condiciones dignas dentro de la } \\
\text { cárcel, respetándoles sus derechos como seres humanos. }\end{array}$ & $15,2 \%$ & $17,1 \%$ & $26,6 \%$ & $26,1 \%$ & $15,2 \%$ & 3,10 & 1,28 \\
\hline Totales (subescala 6) & $13,2 \%$ & $18,8 \%$ & $20,2 \%$ & $29,1 \%$ & $18,7 \%$ & 3,24 & 0,80 \\
\hline
\end{tabular}

Los resultados en la Tabla $7^{49}$ muestran que, el principio asociado a los derechos sociales y de trato a acusados y condenados no es apoyado por la mayoría de los sujetos estudiados $(52,2 \%)$. De esta manera, la mayoría podría considerar que éstos no deberían tener acceso a derechos que vayan más allá de las garantías individuales mínimas y que pudieran suponer costos en materia de programas o políticas sociales; estimarían que al Estado no le debe corresponder un rol social frente a estos sujetos. Es decir, estarían más próximos a una concepción del Estado mínimo más que a una del Estado social de derecho. Por ello, una parte importante de

\footnotetext{
${ }^{47}$ El uso del término "tratado" como inocente, en vez de "considerado" o del verbo "presumir", pudo incidir en que estos ítems cargasen en este factor y no en otro (como en el de Debido Proceso). Se recomienda probar, en otra medición, con ambas formulaciones.

${ }^{48}$ MIR PUIG, Santiago, El Derecho Penal en el Estado Social y Democrático de Derecho, Barcelona: Ediciones Ariel, 1994.

${ }^{49}$ Recordamos que, a diferencia de las subescalas previas, esta tabla debe ser leída de forma inversa. Las respuestas De Acuerdo/Muy de acuerdo indican adhesión, mientras que las Muy en Desacuerdo/En Desacuerdo indican rechazo.
} 
FUENTEALBA, Pablo; LARRAÍN, Beatriz; BARRIGA, Omar. “¿Adhiere la ciudadanía a los principios del derecho penal y procesal penal? El caso del Gran Concepción, Chile”.

los entrevistados podría estar de acuerdo teóricamente con el derecho a defensa material, pero no necesariamente apoyar el financiamiento estatal de dicha defensa mediante impuestos. También existe la posibilidad de que consideren que los derechos humanos básicos deben respetarse, pero que al Estado no le corresponde la función social de mantener las cárceles en óptimas condiciones si éstas suponen gastos públicos importantes. Opuestamente, quienes comparten los supuestos del Estado de derecho en general (debido proceso, legalidad, derecho a defensa material, entre otros), considerarían que muchas de sus nociones teóricas de base serían inseparables de los medios exigidos para su ejecución o realización y que, de esta forma, el rol social mínimo del Estado resulta necesario para que los derechos y garantías (a nivel teórico-conceptual) puedan materializarse.

\section{Discusión y conclusiones}

La investigación presenta limitaciones que deben explicitarse antes de extraer conclusiones. El hecho de que se haya trabajado con una muestra no probabilística y referida a una población específica limita la posibilidad de generalizar los resultados, aunque a nuestro juicio, teniendo presente que el tamaño muestral ha sido adecuado y bastante heterogéneo en términos sociodemográficos, estimamos que el estudio permite obtener un buen primer diagnóstico para esta variable que no ha sido estudiada previamente. Además, la escala no consulta respecto otros delitos (políticos, económicos, drogas, etc.), por lo cual no es posible conocer cómo se comportaría la adhesión frente a éstos. Sin embargo, esto abre las puertas para nuevas investigaciones. Finalmente, a partir de un análisis descriptivo no es posible establecer correlaciones o posibles causas que expliquen los diferentes niveles de adhesión. Por ello, en futuras indagaciones resulta fundamental estudiar las interrelaciones con otras variables tales como percepción de inseguridad, confianza en la justicia y medios de comunicación, entre otras. Incluso sería interesante desarrollar estudios cualitativos a través de entrevistas, focus groups u otras técnicas para profundizar en la comprensión de este fenómeno.

Sin perjuicio de estas limitaciones, ciertas conclusiones importantes pueden extraerse de los análisis anteriores.

En primer lugar, uno de los aspectos más interesantes de la investigación radica en el hecho de que ésta no mide si la ciudadanía apoya las leyes particulares en materia procesal-penal o penal (ya que éstas pueden no ser un reflejo de los principios y, por ejemplo, presentar vacíos legales, errores, etc.), principios penales aislados y/o la ejecución o praxis judicial misma, sujeta a error humano, a decisiones con información incompleta, etc. El estudio, más bien, ha permitido medir de forma válida y confiable el grado de adhesión al conjunto de principios penales (y procesal-penales) con independencia de su realización práctica. Desde nuestra perspectiva, consideramos que la discusión respecto a los niveles de consenso social en torno a las bases de la legislación debiese constituir el primer paso para cualquier debate legislativo serio.

Un segundo hallazgo importante es que la mayor parte de la ciudadanía presenta una posición bastante definida frente a los principios consultados en los ítems, lo cual se refleja en la tendencia hacia una respuesta polar de apoyo o de rechazo ante las afirmaciones, más que hacia respuestas intermedias o ambiguas. Además, se encontró que cuando se comparan los reactivos pareados que miden un mismo principio para diferentes tipos de delito, no hay 
diferencias importantes en los niveles de apoyo o rechazo (cuando se agrupan las alternativas de respuesta), pero que sí existen diferencias muy leves en los promedios. Esto indicaría que la adhesión a los principios penales no depende mucho del tipo de delito consultado, mientras se trate de delitos de alta connotación social. En cambio, la intensidad del rechazo o apoyo, puede variar en alguna medida (por ejemplo, que un sujeto indique en desacuerdo y ante delitos más graves muy en desacuerdo). Teóricamente, podría pensarse que, bajo la perspectiva del punitivismo, la ciudadanía clasificaría al delincuente o sospechoso como un "otro enemigo" (versus la sociedad), simplificando la categoría sin efectuar distinciones.

Un tercer conjunto de hallazgos, y que es el más relevante de acuerdo al objetivo del artículo, se relaciona con los niveles de consenso en torno a los principios del derecho penal (y procesal penal). Se encontró que, en general, menos de la mitad de la ciudadanía aceptaría este conjunto de principios. Esto refleja que, en términos generales, no existiría suficiente consenso que apoye los principios penales iluministas y, más bien, podríamos estar ante la presencia de un importante disenso social, lo cual puede ser preocupante para el sistema de justicia.

Analizando los resultados con mayor precisión, se encontró también que el nivel de adhesión a los principios penales varía dependiendo de la dimensión medida. Así, las cuatro dimensiones con bajos niveles de adhesión (inferiores a 50\%), presentadas desde menor a mayor apoyo, son "Adhesión al principio de intervención mínima y legalidad en la aplicación de penas y medidas", "Adhesión al principio de legalidad penal", "Adhesión al principio de gradualidad de la pena" $y$, finalmente, "Adhesión a los derechos sociales y de trato a condenados y acusados". En cambio, las dos dimensiones con mayor apoyo (sobre 50\%), presentadas desde mayor a menor apoyo, serían "Adhesión al derecho al debido proceso y personalidad de la pena" y "Adhesión al principio de humanidad de la pena desde un sistema estatal de justicia”. Estas dos últimas escalas, a pesar de presentar valores más elevados en comparación con las escalas con bajo apoyo, no reflejarían una adhesión muy elevada considerando que apenas superan un $50 \%$.

El débil consenso en torno a estos principios penales podría denotar un problema de legitimidad desde la opinión pública en su nivel más profundo ante el sistema penal, ya que se produciría en el plano de las creencias sociales ${ }^{50}$. Un bajo nivel de legitimidad en estos principios modernos implicaría, tal vez, que el sistema se estaría sosteniendo por el poder que lo respalda más que por la creencia en su validez y corrección moral ${ }^{51}$. Sin embargo, en este punto no debemos dejar de recordar que los resultados en materias de opinión social dependen de forma significativa de las estrategias de medición empleadas.

Nuestros hallazgos irían en la misma dirección que las tendencias punitivistas exhibidas en otras sociedades y que han sido constatadas por la literatura internacional. De esta forma, diversos autores han mostrado que los ideales penales modernos habrían comenzado a declinar, perdiendo fuerza las creencias en el debido proceso, el ideal de rehabilitación y la aplicación de penas individuales y/o proporcionales, todo lo cual constituiría la esencia de la modernidad y del bienestarismo penal. Así, el derecho penal moderno, que se caracteriza por ser mínimo y poseer limitaciones, comenzaría a ser concebido por la ciudadanía como

\footnotetext{
${ }^{50}$ ORTEGA Y GASSET, José, La Rebelión de las Masas, España: Editorial Espasa-Calpe, 2005.
}

${ }^{51}$ LINZ, La Quiebra, cit. nota 14; WEBER, Economía y Sociedad, cit. nota 17. 
FUENTEALBA, Pablo; LARRAÍN, Beatriz; BARRIGA, Omar. “ ¿Adhiere la ciudadanía a los principios del derecho penal y procesal penal? El caso del Gran Concepción, Chile”.

insuficiente para hacer frente al delito actual dentro de un creciente sentimiento de inseguridad propio de la modernidad tardía (a pesar de que los datos muestran que el delito se reduce o se mantiene estable). Esto se vería reflejado en mayores actitudes punitivas, una demanda por castigos más severos (visión represiva y retributiva de la pena) y en un descontento frente a las sentencias de los jueces, las cuales son vistas como indulgentes ${ }^{52}$. Así, se estaría estimando que las garantías y derechos constituyen limitaciones o trabajas para la labor del Estado frente al delito, por lo que instrumentalmente no serían funcionales, ya que no producen disuasión ${ }^{53}$. Todo esto reflejaría que, en términos de Bourdieu ${ }^{54}$, dos concepciones acerca de la justicia penal podrían encontrarse en disputa dentro del campo jurídico: la lógica del punitivismo y del control versus el ideal penal liberal moderno.

Desde un punto de vista práctico, en el contexto de demandas sociales por cambios legislativos que reflejen la voluntad ciudadana (como ocurre hoy en el caso de Chile), podría presentarse una presión cultural para realizar cambios penales que impliquen un retroceso hacia formas penales pre-modernas. Esta posibilidad se torna bastante probable en el contexto del populismo penal donde los sentimientos y demandas inmediatas de la población (y carentes de mediación experta) pasan a ser consideradas como la fuente de las políticas criminales superando al juicio especialista ${ }^{55}$. De esta forma, la ciudadanía esperaría la instauración de un derecho centrado en la lógica de la defensa social y del control, bajo la imagen de que el delincuente, como "enemigo de la sociedad", no debería ser tratado como persona humana, pudiendo ser despojado de sus derechos fundamentales ${ }^{56}$. En consecuencia, la ciudadanía podría privilegiar políticas y legislaciones penales orientadas a que el Estado la proteja de los "otros enemigos", antes que mantener garantías que la protejan del mismo Estado, rechazando así el sistema garantista. Esto podría poner en riesgo la protección de la persona y de sus derechos fundamentales, bajo el argumento de que estas demandas reflejan los sentimientos y demandas de la población.

Respecto al origen de este fenómeno de cambio en la cultura penal, los datos empíricos no son apropiados para apoyar nuestra explicación por tratarse de un estudio descriptivo. Sin embargo, creemos que es posible pensar en algunas explicaciones posibles para los bajos niveles de consenso encontrados. Desde una perspectiva histórica, sobre el origen de este fenómeno, hipotetizamos que en Chile se habría construido un derecho penal fundamentado en la noción de "persona y de sus derechos fundamentales" concebidos como entidades sagradas que debían protegerse ante la posible violencia estatal, el que se expresó en un sistema de derechos y garantías penales y procesales. Sin embargo, esta construcción no se habría visto acompañada de un adecuado -o continuo- proceso educacional que transmitiera estos principios y creencias a la población para formar, en términos de Ferrari, una cultura

\footnotetext{
52 DIEZ RIPOLLÉS, “El nuevo modelo”, cit. nota 22; DIEZ RIPOLLÉS “De la sociedad del riesgo" cit. nota 22; GARLAND, La Cultura, cit. nota 21.

53 TYLER/BOECKMANN, "Three strikes", cit. nota 25.

${ }^{54}$ BOURDIEU, Pierre; TEUBNER, Gunther, La Fuerza del Derecho, Colombia: Ed. Siglo del hombre, 2000; BOURDIEU, Pierre, Poder, Derecho y Clases Sociales, España: Ed. Desclée de Brouwer, 2001.

${ }^{55}$ GARLAND, La Cultura, cit. nota 20.

56 ZAFFARONI, Eugenio, El Enemigo en el Derecho Penal, Argentina: Ediar Editores, 2006; DIEZ RIPOLLÉS "El nuevo modelo", cit. nota 22; DIEZ RIPOLLÉS “De la sociedad del riesgo", cit. 23; GARLAND “La cultura”, cit. nota 20.
} 
Polit. crim. Vol. 13, № 25 (Julio 2018) Art. 7, pp. 233-263.

[http://www.politicacriminal.cl/Vol_13/n_25/Vol13N25A7.pdf]

jurídica ciudadana ${ }^{57}$. Así, se habría construido e institucionalizado un derecho objetivo y externo fundado en estos principios, pero que no fue interiorizado en las conciencias ciudadanas, perdiéndose la unidad entre la dimensión objetiva del orden jurídico y la dimensión subjetiva de la conciencia ciudadana ${ }^{58}$. Esta interpretación concordaría con lo planteado por Garland en torno al punitivismo que muestra que la institución penal moderna se ha mantenido casi intacta, pero que el cambio se habría producido a nivel cultural, produciéndose un retroceso en materia penal. Así, hechos tales como desconfianza en la capacidad del Estado para proveer seguridad, el sobredimensionamiento del fenómeno del crimen a través de los medios de comunicación, la poca eficacia de políticas de reinserción o el miedo al delito entre otros fenómenos, habrían debilitado los ideales modernos abriendo paso a la cultura del control ${ }^{59}$. En el contexto chileno, esto se vería reflejado en un distanciamiento o desconexión entre la opinión pública y el sistema de justicia, generándose problemas de legitimidad.

Desde la perspectiva de la socialización y de la educación, hipotetizamos que, posiblemente, tampoco se habría desarrollado una forma de pensamiento ético para formar ciudadanos con la capacidad de asumir roles, habilitados para evaluar situaciones desde la perspectiva de "otros" y, de este modo, comprender la racionalidad y universalidad de estos principios penales desde un punto de vista imparcial. Además de desconocer los contenidos de principios penales, los individuos posiblemente presentarían dificultades para pensar hipotéticamente e imaginarse "qué ocurriría si ellos mismos y/o algún cercano o conocido" fuese acusado o condenado por algún delito. ¿Renunciarían al derecho al debido proceso, a la presunción de inocencia, a tribunales imparciales o a la humanidad de las penas? o ¿Tomarían las mismas decisiones si ellos fuesen los jueces? Los sujetos que niegan muchos de estos principios expresados en derechos y garantías a "otros" extraños o anónimos, posiblemente los exigirían si ellos o cercanos suyos fuesen los acusados o condenados, o si ellos debiesen tomar la decisión. Esta eventual inconsistencia en el juicio sería indicio de bajos niveles de desarrollo cognitivo moral. En este sentido, la racionalidad y validez general de los principios se comprendería en la medida en que el sujeto es capaz de adoptar roles $y$, desde una perspectiva imparcial, logra darse cuenta de que los delitos que él o sus cercanos pudieran cometer (o ser acusados) son equivalentes a los que él frecuentemente juzga (propiedad conocida como transferibilidad). Esto, porque la visión desde roles diferentes (y no sólo desde el propio), permite obtener una perspectiva imparcial para generar la regla ${ }^{60}$. Desde otro ángulo, bajos niveles de desarrollo cognitivo moral permiten que la emoción se imponga muchas veces sobre el razonamiento formal en la elaboración del juicio ${ }^{61}$. De esta forma, los individuos posiblemente identificarían lo justo-injusto con un estado emotivo al momento de juzgar: si a los sujetos les produce mayor rechazo el homicidio que el hurto (o "temen" ser víctimas de delitos) o parientes suyos fueron víctimas de delito, no juzgarán en base a principios y razón, sino de acuerdo a las emociones que les produce el hecho. Pensamos así que, posiblemente,

\footnotetext{
${ }^{57}$ FERRARI, Derecho y Sociedad, cit. nota 11.

${ }^{58}$ BERGER/LUCKMANN, La construcción, cit. nota 14.

${ }^{59}$ GARLAND, La Cultura, cit. nota 20.

${ }^{60} \mathrm{HERSH} / \mathrm{PAOLITO} / \mathrm{REIMER}$, El crecimiento, cit. nota 26.

${ }^{61}$ GREENE, Joshua, et al., "The Neural Bases of Cognitive Conflict and Control in Moral Judgment", en Neuron Vol. 44, N² (2004), pp. 389-400, en: http://dx.doi.org/10.1016/j.neuron.2004.09.027 [Fecha de consulta: 25.05.2015].
} 
FUENTEALBA, Pablo; LARRAÍN, Beatriz; BARRIGA, Omar. “ ¿Adhiere la ciudadanía a los principios del derecho penal y procesal penal? El caso del Gran Concepción, Chile”.

el componente emocional podría limitar la comprensión de los principios que fundan el sistema penal el razonamiento en base a éstos para elaborar juicios justos.

Esta forma de comprender los principios en relación a la socialización (educación) y el desarrollo moral podría concordar con los resultados hallados en investigaciones sobre actitudes punitivas. Así, los sujetos tienden a ser menos punitivos cuando se usan metodologías en las cuales se les proporciona información sobre la biografía del acusado o condenado y/o deben asumir el papel de jueces y asignar penas ${ }^{62}$. De esto podría desprenderse que en el momento en el cual un sujeto asume roles (p.e. de juez) o recibe nueva información, desarrolla mayor empatía, puede obtener una visión más general e imparcial, por lo cual el punitivismo se vería reducido. Entonces, si razonamos inversamente, una consecuencia de esto, sería que los niveles de adhesión a los principios (manifiestos) podrían mejorar si es que a la ciudadanía se le provee de mayor información respecto a estos temas, porque potencial o latentemente existiría la disposición a apoyar estos principios. Este aspecto requiere de evidencia empírica que lo apoye, pero podría ser esencial, porque indicaría que los niveles de rechazo a los principios penales serían más bajos de lo que comúnmente se cree, lo cual debería tenerse en consideración por parte de la clase política al momento de elaborar políticas en materia penal ${ }^{63}$.

Sin perjuicio de los límites que presentan estos hallazgos, consideramos que el panorama expuesto podría revelar la necesidad de desarrollar políticas educativas o informacionales en el ámbito de la formación cívico-jurídica. Por una parte, éstas podrían orientarse a transmitir los principios fundamentales del derecho penal a la ciudadanía (y del funcionamiento del sistema en general) y, por otra parte, desarrollar en ésta el nivel ético desde una perspectiva cognitivo evolutiva. De esta forma, la educación e información deberían buscar replicar el conjunto de principios en la conciencia ciudadana y generar una cultura jurídica que permita lograr cierta correspondencia entre el derecho y las opiniones sociales. Si bien existen otros factores que deben estudiarse y, además, estas sugerencias preliminares requerirían de mayor apoyo en nuevas investigaciones, a nuestro juicio pueden constituir primeros lineamientos para la generación de un mayor consenso y legitimidad ante el ordenamiento jurídico sustentado en las ideas del pensamiento penal liberal.

\footnotetext{
62 ROBERTS, et al., "Public Opinion", cit. nota 24; VARONA, "Ciudadanos y actitudes punitivas", cit. nota 24; VARONA, “¿Somos los españoles punitivos?”, cit. nota 23; ROBERTS/HOUGH, Understanding, cit. nota 21.

${ }^{63}$ LARRAURI, Elena, "Populismo punitivo ... y cómo resistirlo”, en Jueces para la Democracia, Vol. 55 (2006), pp. 15-22, en https://dialnet.unirioja.es/servlet/articulo?codigo=1960479 [visitado el 03.08.17].
} 
Polít. crim. Vol. 13, № 25 (Julio 2018) Art. 7, pp. 233-263.

[http://www.politicacriminal.cl/Vol_13/n_25/Vol13N25A7.pdf]

\section{Bibliografía}

BACIGALUPO, Enrique, Derecho Penal y el Estado de derecho, Santiago: Ed. Jurídica de Chile, 2005.

BERGER, Peter; LUCKMANN, Thomas, La construcción social de la realidad, España: Ed. Amorrortu, 2003.

BOBBIO, Norberto, Liberalismo y Democracia, México: Ed. FCE, 1997.

BOURDIEU, Pierre; TEUBNER, Gunther, La Fuerza del Derecho, Colombia: Ed. Siglo del hombre, 2000.

BOURDIEU, Pierre, Poder, Derecho y Clases Sociales, España: Ed. Desclée de Brouwer, 2001.BUSTOS, Juan; HORMAZÁBAL, Hernán, Nuevo sistema de Derecho Penal, España: Ed. Trotta, 2004.

CALDEIRA, Gregory; GIBSON, James, "The etiology of the public support of for the supreme court, en American Journal of Political Science", Vol. 36, № 3 (1992) pp. 635-664 en http://www.jstor.org/stable/2111585 [Fecha de Consulta: 05.08.2017].

DAMMERT, Lucía; MALONE, Mary Fran, "Fear of Crime or Fear of Life? Public Insecurities in Chile", Bulletin of Latin American Research 22(1) (2003), pp. 79-101, en: http://dx.doi.org/10.1111/1470-9856.00065 [visitado el 22.05.15].

DIEZ RIPOLLÉS, José Luis, "El nuevo modelo Penal de la seguridad ciudadana", Revista Electrónica de Ciencia Penal y Criminología, Vol 6 Art.3 (2004), en: http://criminet.ugr.es/recpc/06/recpc06-03.pdf [Fecha de consulta: 03.08.2017].

DIEZ RIPOLLÉS, José Luis, "De la sociedad del riesgo a la seguridad ciudadana: un debate desenfocado", en Revista Electrónica de Ciencia Penal y Criminología. Vol. 7 Art. 3 (2005), en http://criminet.ugr.es/recpc/07/recpc07-01.pdf [Fecha de consulta: 03.08.2017].

DURKHEIM, Émile, La división del trabajo social, Madrid: Ed. Akal, 1982.

ETCHEBERRY, Alfredo, Derecho Penal: Parte general, Santiago: Ed. Jurídica de Chile, 1998.

FERRARI, Vicenzo, Derecho y Sociedad. Elementos para una Sociología del Derecho, Colombia: Editorial Universidad Externado de Colombia, Edición Kindle, 2012. 
FUENTEALBA, Pablo; LARRAÍN, Beatriz; BARRIGA, Omar. “ ¿Adhiere la ciudadanía a los principios del derecho penal y procesal penal? El caso del Gran Concepción, Chile".

FUCITO, Felipe, Sociología del Derecho. Del Orden Jurídico y de sus Condicionantes Sociales, Argentina: Ed. Universidad, 1999.

FUENTEALBA, Pablo; ROJAS, Juan; BARRIGA, Omar, "Diferencias en la precepción de inseguridad a nivel cognitivo y emocional de acuerdo al perfil sociodemográfico y político. Estudio del Gran Concepción, Chile”, en Revista Política Criminal, Vol. 11, $\begin{array}{lllll}\mathrm{n}^{\circ} & 2 & (2016) & \mathrm{pp} . & 620-655,\end{array}$ http://www.politicacriminal.cl/Vol_11/n_22/Vol11N22A8.pdf [Fecha de consulta: 25.07.2017].

FUENTEALBA, Pablo; BARRIGA, Omar, "Primera aproximación a la construcción de una Escala de Adhesión a los principios del Derecho Penal (EAPDP)". Estudio Piloto en el Conurbano del Gran Concepción, Chile", en Revista Internacional de Sociología, Vol. 75, No2 (2017), pp. e060, en http://dx.doi.org/10.3989/ris.2017.75.2.15.103 [Fecha de consulta: 28.07.2017].

GARLAND, David, La cultura del control, España: Ediciones Gedisa, 2005.

GIBSON, Chris et al., "Social Integration, Individual Perceptions of Collective Efficacy, and Fear of Crime In Three Cities", Justice Quarterly, Vol. 19, № 3 (2002), pp. 537-564, en: http://dx.doi.org/10.1080/07418820200095341 [visitado el 26.07.2017].

GREENE, Joshua, et al., "The Neural Bases of Cognitive Conflict and Control in Moral Judgment", en Neuron Vol. 44, $\mathrm{N}^{\circ} 2$ (2004), pp. 389-400, en: http://dx.doi.org/10.1016/j.neuron.2004.09.027 [Fecha de consulta: 25.05.2015].

HERSH, Richard; PAOLITO, Diana; REIMER, Joseph, El crecimiento moral, de Piaget a Kohlberg, Madrid: Ediciones Narcea, 1988.

INSTITUTO NACIONAL DE ESTADÍSTICAS, “Actualización de Población 2002-2012 y Proyecciones 2015-2020 Provincia de Concepción”, Santiago de Chile: INE (2015), en:

http://www.inebiobio.cl/archivos/files/pdf/poblacion/Proyecciones/PRESENTACIO $\mathrm{N}$

\%20PROYECCIONES\%20DE\%20POBLACION\%20PROV\%20CONCEPCION.pd f [visitado el 05.07.16].

KANT, Immanuel, Fundamentación para una Metafísica de las costumbres, Madrid: Ed. Alianza, 2012.

KANT, Immanuel, Principios Metafísicos del Derecho, Madrid: Librería Victoriano Suárez Jacometrezo, 1879; 2012.

LARRAURI, Elena. "Populismo punitivo ... y cómo resistirlo", en Jueces para la Democracia, Vol. $55 \quad$ (2006), p. $\quad 15-22, \quad$ en https://dialnet.unirioja.es/servlet/articulo?codigo=1960479 [visitado el 03.08.17]. 
Polit. crim. Vol. 13, № 25 (Julio 2018) Art. 7, pp. 233-263.

[http://www.politicacriminal.cl/Vol_13/n_25/Vol13N25A7.pdf]

LINZ, Juan, La Quiebra de las Democracias, Madrid: Ediciones Alianza, 1987.

MATHIESEN, M.E. et al. "Familia, Permisividad y Juicio Moral en Estudiantes de Enseñanza Media de la Provincia de Concepción", Revista Psykhé Vol. 13, №1 (2004), pp. 3-20, en: http://www.scielo.cl/scielo.php?script=sci_arttext\&pid=S071822282004000 100001\&lng=es\&nrm=iso [fecha de consulta: 20.10.2015].

MAZZUCA, Sebastián, "Legitimidad, Autonomía y Capacidad: Conceptualizando (una vez más) los poderes del Estado", Revista de Ciencia Política - Pontificia Universidad Católica de Chile, Vol. 32, N³ (2012), pp. 545-560, en: http://www.scielo.cl/scielo.php?pid=S0718090X20120003000 02\&script=sci_arttext [fecha de consulta: 8.10.2015]MIR PUIG, S., El Derecho Penal en el Estado Social y Democrático de Derecho, Barcelona: Ediciones Ariel,1994.

MIR PUIG, Santiago, El Derecho Penal en el Estado Social y Democrático de Derecho, Barcelona: Ediciones Ariel, 1994.

ORTEGA Y GASSET, José, La Rebelión de las Masas, España: Editorial Espasa-Calpe, 2005.

ROBERTS, Julian et al., Penal populism and public opinion: five lessons from five countries, United Kingdom, Ediciones Oxford University Press, 2003.

ROBERTS, Julian, et al., "Public Opinion Towards the Lay Magistracy and the Sentencing Council Guideline: the effects of information on attitudes", en British Journal of Criminology, Vol. 52, $\mathrm{N}^{\mathrm{o}} 6$ (2012) pp. 1072-1091 en: https://academic.oup.com/bjc/article-lookup/doi/10.1093/bjc/azs024 [Fecha de consulta 29.07.2017].

ROBERTS, Julian; HOUGH, Michael, Understanding public attitudes to criminal justice, United Kingdom, Ediciones Open University Press, 2005.

ROBLES, V., "La complementación de la discusión de dilemas con la lectura teórica para una eficaz intervención en el juicio moral", International Journal of Psychological Research, Vol. 6, $\quad \mathrm{N}^{\circ} 1 \quad$ (2013), pp. 84-93, en: http://www.scielo.org.co/pdf/ijpr/v6n1/v6n1a10.pdf [Fecha de consulta: 10.012015].

RUIZ, Enrique, El Derecho Penal Sustantivo y el Proceso Penal. Garantías constitucionales básicas en la realización de justicia, España: Editorial Colex, 1997.

SILVA, Jesús-María, Aproximaciones al Derecho Penal Contemporáneo, España: Editorial José María Bosch,1992.

TYLER, Tom; BOECKMANN, Robert, "Three strikes and you are out, but why? The psychology of public support for punishing rule-breakers", en Law and Society Review, Vol. 31, $\quad \mathrm{N}^{\mathrm{o}} 2$ (1997), pp. 237-266 en 
FUENTEALBA, Pablo; LARRAÍN, Beatriz; BARRIGA, Omar. “ ¿Adhiere la ciudadanía a los principios del derecho penal y procesal penal? El caso del Gran Concepción, Chile”.

http://www.jstor.org/stable/3053926?seq=1\#page_scan_tab_contents [Fecha de Consulta: 04.08.2017].

VARONA, Daniel. "Ciudadanos y actitudes punitivas: un estudio piloto de población universitaria española”, en Revista española de Investigación Criminológica, Vol. 6

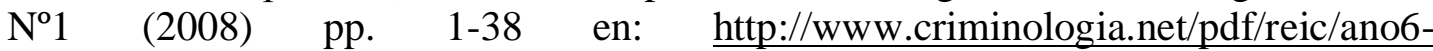
2008/a62008art1.pdf [Fecha de consulta: 27.07.2017]

VARONA, Daniel. “¿Somos los españoles punitivos?: actitudes punitivas y reforma penal en España”, Revista InDret, Vol. 9, No1 (2009), pp. 1-31 en: http://www.indret.com/pdf/599.pdf [Fecha de consulta: 25.07.2017].

WEBER, M., Economía y Sociedad, México: Ediciones FCE, 2002.

ZAFFARONI, Eugenio, Derecho Penal. Parte General, Argentina: Ediar Editores, 2001.

ZAFFARONI, Eugenio, El Enemigo en el Derecho Penal, Argentina: Ediar Editores, 2006. 